\title{
Cardioprotective Effects of Dietary Phytochemicals on Oxidative Stress in Heart Failure by a Sex-Gender-Oriented Point of View
}

\author{
Klara Komici $\mathbb{D},{ }^{1}$ Valeria Conti $\mathbb{D},{ }^{2}$ Sergio Davinelli $\mathbb{D},{ }^{1}$ Leonardo Bencivenga $\mathbb{D},{ }^{3}$

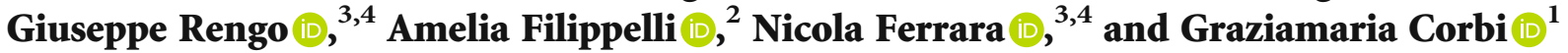 \\ ${ }^{1}$ Department of Medicine and Health Sciences, University of Molise, Via Francesco De Sanctis, 1, 86100 Campobasso, Italy \\ ${ }^{2}$ Department of Medicine, Surgery and Dentistry "Scuola Medica Salernitana", University of Salerno, Via S. Allende, Baronissi, \\ 84081 Salerno, Italy \\ ${ }^{3}$ Department of Translational Medical Sciences, University of Naples Federico II, Via Pansini, 5 -, 80138 Naples, Italy \\ ${ }^{4}$ Istituti Clinici Scientifici Maugeri SpA Società Benefit" (ICS Maugeri SpA SB), Via Bagni Vecchi, 1, 82037 Telese Terme (BN), Italy
}

Correspondence should be addressed to Sergio Davinelli; sdavinelli@hsph.harvard.edu

Received 31 May 2019; Revised 3 November 2019; Accepted 29 November 2019; Published 10 January 2020

Guest Editor: Sabato Sorrentino

Copyright (c) 2020 Klara Komici et al. This is an open access article distributed under the Creative Commons Attribution License, which permits unrestricted use, distribution, and reproduction in any medium, provided the original work is properly cited.

\begin{abstract}
Dietary phytochemicals are considered an innovative strategy that helps to reduce cardiovascular risk factors. Some phytochemicals have been shown to play a beneficial role in lipid metabolism, to improve endothelial function and to modify oxidative stress pathways in experimental and clinical models of cardiovascular impairment. Importantly, investigation on phytochemical effect on cardiac remodeling appears to be promising. Nowadays, drug therapy and implantation of devices have demonstrated to ameliorate survival. Of interest, sex-gender seems to influence the response to HF canonical therapies. In fact, starting by the evidence of the feminization of world population and the scarce efficacy and safety of the traditional drugs in women, the search of alternative therapeutic tools has become mandatory. The aim of this review is to summarize the possible role of dietary phytochemicals in HF therapy and the evidence of a different sex-gender-oriented response.
\end{abstract}

\section{Introduction}

Despite recent advances in clinical/diagnostic tools and therapies, the incidence and prevalence of heart failure (HF) show a steady increase [1]. From the pathophysiological point of view, this condition is associated with chronic overactivation of the adrenergic system [2-4], endothelial dysfunction, increased oxidative stress [5], and mitochondrial dysfunction; all these abnormalities are involved in the development and the progression of HF [6]. Nowadays, although drug therapy and the implantation of devices have demonstrated to increase survival, their use is limited by important side effects [7] that worsen the HF patients' quality of life. Moreover, the demographic changes in population composition have recently determined an increasing difficulty in the therapeutic approach of HF. Starting with the evidence of the feminization of the world population and the scarce efficacy and safety of the traditional drugs in women, the search for alternative therapeutic tools has become mandatory. Despite sex referring to biological factors and gender to psychosocial, cultural, and environmental factors, it is difficult to separate one from each other. Both are multidimensional, entangled, and interactive factors that may influence the pharmacological response. Then, it has been suggested that the simultaneous use of sex-gender terms is more appropriate [8]. From this view, the dietary phytochemicals appear, thanks to their safety and efficacy, the ideal candidate for the HF therapy in women. The aim of this review is to summarize the cardioprotective effects of natural products in HF therapy and the evidence of a different sex-gender-oriented response to oxidative stress modulation.

\section{Sex-Gender and HF}

2.1. Sex-Gender Differences in HF. The prevalence of HF affects about 2.6 million women and 3.1 million men in the 
USA [9], with higher prevalence in advanced age. However, women tend to be older than men at diagnosis and exhibits a different phenotype: the HF with preserved ejection fraction (HFpEF) is more frequent in women and new onset of $\mathrm{HF}$ with reduced ejection fraction (HFrEF) in men [10]. Moreover, despite women with present $\mathrm{HF}$ at an older age, where comorbidities are more frequent, some studies showed that women have a lower cardiovascular and all-cause mortality $[11,12]$, suggesting that the phenotypic differences in HF presentation and prognosis between women and men may be the consequence of progressive, sex-specific changes in cardiac and vascular physiology. Furthermore, the menopausal transition may influence the development of cardiovascular risk factors in women [13]. Women demonstrate greater, body-size-adjusted increases in the left ventricle (LV) wall thickness and concentric remodeling than men, which predispose to myocardial stiffness and diastolic dysfunction. Furthermore, the age-related increase in left ventricle ejection fraction (LVEF) is more pronounced in women [14]. Animal models indicate that female rats are more likely to develop concentric myocardial hypertrophy [15]. These differences in LV remodeling are consistent with the highest likelihood of women to present HFpEF. On the other hand, men are more likely to show age-related increases in the LV cavity dimension and LV systolic dysfunction, which are hallmarks of HFrEF [14]. Consistent with these observations, male rats generally develop eccentric myocardial hypertrophy and fibrosis [15]. These different underlying processes could be responsible for the potential differences in drug tolerance and toxicity [16] to therapeutic interventions in women. Indeed, the most common therapeutic modalities for HF currently include therapies effective in the treatment of HFrEF; conversely, their efficacy in the treatment of HFpEF, the most common HF type in women, has been largely inconclusive [17]. Then, the understanding of the differences in pathophysiological response requires also the study of the different molecular pathways implicated in the different phenotypes of HF.

While HFrEF is linked with ischemia and cardiomyocyte loss [18], HFpEF is associated with advanced age [19], obesity [20], and hypertension [21]. These comorbidities induce the extensive myocardial expression of endothelial adhesion molecules [22]. A progressive reduction in the capillary density (i.e., microvascular rarefaction) in HFpEF hearts [23] activates a transforming growth factor- $\beta$ - (TGF $\beta$-) signaling cascade that is profibrotic and leads to myocardial collagen accumulation [24, 25].

\subsection{Role of Oxidative Stress in HF. Activation of the sympa-} thetic nervous system and the renin-angiotensinaldosterone axis in HF is associated with oxidative stress, and it is already well-established that, in the genesis of HF, reactive oxygen species (ROS) production within the myocardium and the vasculature is substantially increased $[5,26,27]$. Oxidative stress is defined as an imbalance between the production of ROS and the endogenous antioxidants defense system $[28,29]$.

ROS are high reactivity oxygen-based chemical species that include free radicals, such as superoxide $\left(\mathrm{O}^{-}\right)$, hydroxyl radical $(\mathrm{OH})$, and nonradical molecules capable of generating free radicals, such as hydrogen peroxide ( $\mathrm{H} 2 \mathrm{O} 2)$. The role of the antioxidant defense system is to scavenge and degrade ROS to nontoxic molecules. Well-known enzymes with antioxidant properties are superoxide dismutase (SOD), glutathione peroxidase, and catalase [30]. Mitochondria, nicotinamide adenine dinucleotide phosphate (NADPH) oxidases (NOXs), and uncoupled NO synthase (NOS) are considered relevant sources of ROS generation during HF development. Under physiological conditions, $\mathrm{NADH}$ and FADH2 generation is required for sequential redox reactions in mitochondria and ATP production, and minimal quantity of ROS is produced. In HF models, increased generation of $\mathrm{O}^{-}$, hydroxyl radicals, and $\mathrm{H} 2 \mathrm{O} 2$ has been identified an $[31,32]$. Moreover, the myocardial expression of ROS correlates with left ventricular contractile dysfunction. Although the majority of experimental models are performed on mice or rats following myocardial infarction induction [33], data from clinical studies in patients with ischemic cardiomyopathy also confirmed the relationship between increased levels of ROS and left ventricular dysfunction [34]. In fact, in conditions such as hypoxia or ischemia where oxygen availability is reduced, mitochondrial generation of ROS is enhanced and this can contribute to cardiomyocyte damage $[28,35]$. In addition, increased ROS levels influence mitochondrial DNA damage which may lead to additional mitochondrial ROS generation [36]. $\mathrm{Ca}^{2+}$ signaling alternations are other hallmarks for $\mathrm{HF}$, and systolic $\mathrm{Ca}^{2+}$ transient amplitude is reduced with a slower rate-ofrise. Consequences of these modifications are decreased cardiomyocyte shortening, slower contractile kinetics, and delayed relaxation. At the molecular level, these findings are explained by an increased leak of $\mathrm{Ca}^{2+}$ from the sarcoplasmic reticulum via ryanodine receptors, downregulation of sarcoplasmic reticulum ATPase (SERCA2A) together with upregulation of $\mathrm{Na} / \mathrm{Ca}^{2+}$ exchanger [37]. These perturbations at the mitochondrial level affect the NADH and NADPH activity, enhancing the prooxidative state and increasing mitochondrial ROS production [38].

NADPH oxidase has been reported as a major source of ROS generation in HF [39]. Endothelial cells and activated leukocytes are main sources of NADPH oxidase ROS generation. Different studies over the last decade have tried to investigate the role of specific catalytic units of NADPH oxidase such as Nox 2 and Nox4 in HF development and progression [40, 41]. Indeed, genetic deletion of Nox2 in animal models of systolic dysfunction improved left ventricular remodeling. Pressure overload models of HF triggers NOS uncoupling, generation of ROS, and its inhibitionattenuated cardiac dilatory remodeling and reduced ROS level [42]. Of interest, a crosslink between NADPH oxidase activation and mitochondrial dysfunction mediated by Angiotensin II has been also described [43]. Angiotensin II initially activates NADPH oxidase and production of $\mathrm{O}^{-}$ and $\mathrm{H} 2 \mathrm{O} 2$, which induces mitochondrial generation of ROS and modulates endothelial NO production.

As previously described, whereas in HF genesis and progression, a prominent role is ascribed to ROS production and accumulation, exhaustion of endogenous antioxidants 
defense system has been reported in myocardial infarction animal models [43], and inversely, overexpression of antioxidant enzymes such as glutathione peroxidase improves left ventricular remodeling in ischemia/reperfusion $\mathrm{HF}$ model $[44,45]$.

Several murine models of systolic HF have showed reduction of other antioxidative defenses as SOD and NAD [33, 46-49]. Of interest, depleted blood glutathione levels were significantly associated with symptomatic status in patients with ischemic cardiomyopathy [50]. In contrast, in pacing induced HF experimental model, no modification of antioxidant defense enzymes including SOD, glutathione peroxidase, and catalase was described indicating that oxidative stress in this type of HF might be primarily caused by the enhancement of ROS generation rather than the decline in antioxidant defenses [51]. Preclinical studies have revealed the existence of an uncoupled sNO enzyme state where $\mathrm{NO}$ release was replaced by $\mathrm{O}^{-}$production, and inhibition of eNOS resulted in decreased ROS generation $[52,53]$. Furthermore, AT1 receptor blockage reduced ROS production, improved NO release, and cardiac remodeling in idiopathic-dilated cardiomyopathy experimental model [54]. Interestingly, in an experimental model of HFpEF, decreased myocardial NO levels lead to increased cytosolic $\mathrm{Ca}^{2+}$ and diastolic dysfunction and these effects were restored by supplementation with eNOS cofactor tetrahydrobiopterin [55]. It is believed that in $\mathrm{HFrEF}$, major generation of ROS occurs in cardiomyocytes and this process induces maladaptive remodeling through the activation of cardiomyocyte necrosis, apoptosis, and reactive cardiac fibrosis, while HFpEF, a chronic proinflammatory state induced by comorbidities, is responsible for ROS generation in endothelial cells. Further, this process effects cardiac remodeling by inducing cardiomyocyte hypertrophy and myocardial stiffness.

2.3. Sex-Gender Differences in Oxidative Stress. Notably, clinical and experimental data suggested a greater antioxidant potential in females over males [56]. In particular, ROS production is higher in the vascular cells from males than in the cells from females $[57,58]$, suggesting that women are less susceptible to oxidative stress. Indeed, oxidative stress occurs as a result of an imbalance between ROS production and the antioxidant defense system. Brandes et al. [59] found that, under normal conditions, the male rat aortas generated more superoxide radicals than the female aortas. In contrast, a study [60], comparing coronary artery disease (CAD) in postmenopausal women with males, demonstrated that, even in the control group who did not have CAD, postmenopausal women had higher oxidative stress levels than men, with women with CAD having ROS levels almost three times higher than men with CAD [60]. This suggests the possibility that estrogen lowers oxidative stress in premenopausal females. These findings could explain, at least in part, the different HF phenotype between genders.

A difference in the expression and/or activities of antioxidant enzymes between males and females may also be explained by the different antioxidant response. Regarding superoxide dismutase (SOD), there is no uniform consensus on gender differences. Chen et al. [61] reported no significant difference in SOD activity levels between male and female mice in the heart, while Barp et al. [62] in female rats' heart found higher SOD activity levels than in males. Interestingly, the SOD activity levels in both male and female rats were significantly decreased after castration compared to their respective controls [62], suggesting a possible association between sex hormones and SOD activity levels. It is more likely that males could have higher levels of superoxide production due to NADPH oxidase activity. A study [63] found no gender difference in the vascular response to hydrogen peroxide, thus suggesting that the difference between male and female ROS production could be due to NADPH oxidase activity. In particular, NADPH oxidase subunits were found to exhibit gender discrepancies. Expression of Nox1 and Nox4 was higher in males than in females, suggesting that gender differences in superoxide formation could be due to the activity of these two subunits [63]. Stimuli that activate Nox4 include ischemia, hypoxia, and adrenergic stimuli, all present and enhanced in the setting of HF. The implications of Nox 4 for HF are still controversial. Kuroda et al. [41] demonstrated that, in cardiac-specific Nox4 knockout mice, the upregulation of Nox4 was primarily responsible for the increased mitochondrial $\mathrm{O} 2-$ production in response to pressure overload. Furthermore, Nox4 played a critical role in mediating mitochondrial dysfunction, apoptosis in cardiac myocytes, and eventual LV dysfunction in response to pressure overload [41]. On the other hand, other evidence $[64,65]$ showed that both Nox2 and Nox4 contribute to the increase in ROS and injury by ischemia/reperfusion. However, low levels of ROS produced by either Nox 2 or Nox 4 regulate HIF- $1 \alpha$ and PPAR- $\alpha$, thereby protecting the heart against the ischemia/reperfusion injury, suggesting that Nox also act as a physiological sensor for myocardial adaptation $[64,65]$.

Higher levels of Nox1 and Nox 2 in porcine isolated coronary arteries (PCA) were found in males, although Nox4 was higher in females [66]. It could be possible that higher expression of Nox subunits in men could in part explain why males exhibit higher levels of oxidative stress than females. Wong et al. [66] also showed that the Nox subunits played a role in endothelium-derived hyperpolarization in PCAs of males but not females, which could further show that an increased level of Nox activity is indicative of more oxidative stress in males. Also, ovariectomy of female rats $\mathrm{NADPH}$ oxidase activity treatment with $17 \mathrm{~b}$-estradiol restored NADPH-oxidase activity to normal levels [63]. These data further suggest that estrogen may contribute to decreased oxidative stress, possibly via the regulation of NADPH oxidase activity especially the Nox1, Nox2, and Nox4 subunits. It has also been suggested that males have higher NADPH oxidase activity levels due to an angiotensin II-mediated mechanism. In endothelial cells, 17b-estradiol receptors (E2-R) signaling exerts anti-inflammatory effects by augmenting eNOS-induced NO signaling [67], attenuating the major cellular source of ROS and NADPH oxidase $[40,68]$, and inhibiting the expression of endothelial leukocyte adhesion molecules such as vascular cell adhesion molecule 1 (VCAM1) and intercellular cell adhesion molecule 
(ICAM1) [69]. In cardiomyocytes, E2 stimulates the expression of the prosurvival kinase, Akt, which inhibits cellular apoptosis in women [70] and promotes cell survival [71]. Moreover, E2 attenuates CM remodeling in response to pressure overload [72] and augments myocardial angiogenesis, thereby increasing capillary density $[25,73]$.

The different response to ROS could partially also explain the difference in the therapy's efficacy. A study on spontaneously hypertensive rats shows that females are less susceptible to angiotensin II-mediated increases in oxidative stress [27]. Another study with wild-type mice showed that superoxide production decreased in male Nox 2 knockout mice, but not in females, suggesting that Nox 2 plays a role in mediating ROS generation in response to angiotensin II in males but not in females [74]. Another study [75] found that males have higher levels of p47, which is a cytoplasmic subunit of NADPH oxidase. This subunit is connected to the angiotensin II system as angiotensin II binds to the angiotensin type I receptor, which then induces the phosphorylation of $\mathrm{p} 47$. Then, there is a translocation of the phosphorylated p47 into the plasma membrane, which is an essential step in the assembly of the NADPH oxidase complex and the initiation of ROS production. This study found that $\mathrm{p} 47$ levels did not change with estrogen levels, thus representing an estrogen-independent mechanism, suggesting that regulation of NADPH oxidase activity may be more complex and likely the result of a combination of estrogen-dependent and estrogen-independent mechanisms [75]. Male spontaneously hypertensive rats were found to have higher levels of superoxide generation than female rats [76]. Gender differences associated with NADPH oxidase activity are responsible for the higher levels of superoxide in males. Male spontaneously hypertensive rats also have lower levels of nitric oxide (NO) due to its degradation by superoxide, thus contributing to oxidative stress [76]. In a study with lipopolysaccharides (LPS) to induce inflammation and oxidative stress [77], it was found that female rats treated with LPS had a greater stroke volume and cardiac output compared to male rats, while male rats with LPS treatment were found to have systolic dysfunction after 24 hours whereas female rats did not [77]. These data reveal a significant sex difference associated with LPS injection and that female rats seem to recover cardiac function faster than male rats. Sun et al. [78] have reported that females have increased levels of eNOS associated with the cardiomyocyte-specific caveolin and that after ischemia/reperfusion, females have increased translocation of nNOS to caveolin-3. Sun et al. [78] further showed that in females showing less ischemia/reperfusion injury than males, females have increased S-nitrosylation of the L-typecalcium channel, which results in decreased calcium entry via the L-type calcium channel. The increase in NOS in females under conditions associated with increased calcium (which activates NOS) results in increased S-nitrosylation of the L-type calcium channel, less calcium entry, and therefore less calcium loading during ischemia. Previous studies [79-81] have shown that reducing calcium levels during ischemia is cardioprotective. Overall, the results of all these studies have demonstrated that there is a clear association between gender, oxidative stress, and HF. The question remains whether these gender differences with oxidative stress explain the gender differences in overarching diseases [82].

Moreover, recently, some studies [83-85] have been carried out to decipher whether a disparity in the response to stress could take place in cells coming from males and females concerning the chromosomal asset. XX and XY cells, independently from their origin (e.g., mice, rats, and humans) and histotype (e.g., muscular and endothelial vessel cells, cardiomyocytes, neurons, fibroblasts), display different responses to stress: $\mathrm{XX}$ cells are more prone to autophagic cytoprotection and senescence, whereas XY cells are easier and undergo apoptosis. Under the same stress, e.g., oxidative, a sex disparity can be found in intracellular parameters of importance in cell fate [86]. This has been attributed to sexbiased miRNAs, which are regulated by estradiol or are expressed from loci on the $\mathrm{X}$ chromosome due to incomplete $\mathrm{X}$ chromosome inactivation [25]. Interestingly, whereas estradiol-induced miRNAs predominantly appear to serve protective functions, many $\mathrm{X}$-linked miRNAs have been found to challenge microvascular and myocardial integrity. Thus, menopausal estradiol deficiency, resulting in protective miRNA loss and the augmentation of X-linked miRNA expression, may contribute to the female-specific cardiovascular etiology in HF with near-normal/normal LVEF [25].

\section{Dietary Phytochemicals and HF}

Dietary phytochemicals include a large group of nonnutrient compounds from a wide range of plant-derived foods and chemical classes $[87,88]$. Polyphenols are the most commonly studied classes of dietary phytochemicals. They are considered an innovative nutritional strategy that helps to reduce cardiovascular risk factors, with a beneficial role in endothelial function and oxidative stress as demonstrated by experimental and clinical models of cardiovascular impairment $[89,90]$. Importantly, investigation on phytochemical effect on cardiac remodeling appears to be promising [91]. Indeed, a large number of experimental models report that phytochemicals acting through the modulation of oxidative stress response to ischemic injury reduce cardiomyocyte apoptosis, necrosis, and cardiac fibrosis [92, 93]. Dietary phytochemicals are commonly present in fruits, vegetables, nuts, spices, coffee chocolate, cacao, and wine. Although these compounds are well presented in nature, some limits characterize their bioavailability: it is affected by food preparation techniques, gastrointestinal metabolism, and microbial flora. Also, data regarding phytochemicals active metabolites in tissues are rare and difficult to apply [94]. In this section, we initially describe the characteristics of polyphenols and phytosterols and their role on oxidative stress and endothelial function, and then we discuss the most relevant findings of their applications in experimental and clinical models of HF.

\subsection{Polyphenols}

3.1.1. Classification. Polyphenols include a large class of natural compounds of plant origin found in fruits, legumes, 
vegetables, cereals, spices, nuts, olives, chocolate, tea, coffee, beer, and wine [95]. They are water-soluble compounds characterized by one or more phenolic rings classified in flavonoid and nonflavonoids.

Flavonoids chemically consist of two phenyls and one heterocyclic ring and are further subdivided into flavones, flavanols, flavanones, flavonols, isoflavones, and anthocyanidins. Well-known examples of flavonoids are quercetin, catechin, epigallocatechin, genistein, hesperidin, delphinidin, apigenin, and luteolin. Blueberries, parsley, black tea, wine, and cocoa are rich in flavonoids [96, 97].

Nonflavonoids include phenolic acids, stilbenes, and lignans, comprising products like curcumin, resveratrol, tannins, chlorogenic acid, gallic acid, and caffeic acid.

Polyphenols are secondary plant metabolites characterized by astringent color, bitterness, and protection against ultraviolet radiation and pathogens [98]. They are firstly hydrolyzed by intestinal enzymes or by colonic microflora and poorly absorbed. However, it is reported that resveratrol is characterized by a good absorption rate and by a very low bioavailability: $92 \%$ of the administered dose was excreted in urine and feces [99]. Their plasma concentration depends also on their ability to bind to metal cations and proteins. Once reaching the colon, they are metabolized by microbiota producing several bacterial metabolites [95]. During phase I metabolism, isoflavones and flavonoids undergo O-demethylation and hydroxylation catalyzed by CYP1A1, CYP1A2, and CYP1B1 [100]. Phase II metabolism is characterized by methylation, glucuronidation, sulfation, and ring-fission metabolism. Catechol-Omethyltransferase (COMT) and sulfotransferase SULT1A1 and SULT1A3 are described as key enzymes involved in this process in mice, rats, and humans [101]. A considerable number of studies [102-104] report that in phase III metabolism, dietary phytochemicals influence ATP-dependent efflux pumps such as multidrug resistance-associated glycoprotein (MGP), p glycoprotein (PGP), and organic anion transporters (OAT) by inhibiting their activity.

3.2. Mechanisms on Oxidative Stress. Polyphenols have strong antioxidant properties, and their activity on oxidative stress is determined by their capacity to (a) upregulate antioxidant defenses, (b) scavenge and interact with ROS, and (c) inhibit enzymes involved in ROS generation. Polyphenols interact with the hydrophobic core of the membrane layer avoiding ROS access. In the same way, they affect the oxidation rate of proteins and lipids [105]. Furthermore, structural features of polyphenols, as hydroxyl groups, catechol group on the B-ring, and carbonyl group in the C-ring influence the scavenging of metal ion chelation and free radicals. Indeed, quercetin is characterized by iron-chelating properties [106]. Modification of hydrogen peroxidase, nitric oxide synthases (NOS), cyclooxygenase (COX), and lipoxygenase (LOX) has been demonstrated, and their inhibition significantly reduces the level of key mediators and regulators of proinflammatory response as NO, leukotrienes, and prostaglandins [107].

It has been proposed that an indirect antioxidant enzymatic defense is due to hormetic mechanisms where poly- phenols induce an adaptive cellular response to oxidative stress [108-110]. Different investigations have reported that the physiological action of polyphenols on endothelium is related to (a) endothelial NO synthase activity production, (b) increase of eNOS expression, (c) inhibition of endothelin-1 synthesis, (d) attenuation of PGI2 synthesis, and (e) intracellular Ca2+ pathways. Several pioneer studies have reported that polyphenols produced endotheliumdependent vasorelaxation that was generally associated with increased NO release and cyclic GMP formation and blunted by inhibitors of NO synthase, indicating that it was mediated by the NO-cyclic GMP pathway [111]. All these pathways are involved in the HF genesis and progression, suggesting a possible role of dietary phytochemicals in this syndrome.

\subsection{Polyphenols and HF in Experimental Models}

3.3.1. Quercetin. Quercetin is abundant in grains, red onions, apples, and citrus fruits, with antioxidant, anti-inflammatory, and anticlotting properties [112]. In rodent models of hypertension, it has demonstrated a dose-dependent antihypertensive effect [113]. In particular, quercetin treatment reduces vascular production of ROS and was associated with downregulation of NADPH oxidase subunit [114]. It has been reported that, in experimental models of hypertension, quercetin attenuates left ventricular hypertrophy, pressure overload, and isoproterenol-induced cardiac hypertrophy [113, $115,116]$. Then, from these results, it may be hypothesized that there is a plausible effect of quercetin in HFpEF. Indeed, quercetin demonstrated to reduce plasmatic levels of ROS, angiotensin, aldosterone, TGF $\beta 1$ myocardial expression, and collagen deposition [116]. Panchal et al. [117] indicated that quercetin's positive effect on collagen deposition is also related to the inhibition of the NF- $\kappa \mathrm{B}$ signaling pathway and the activation of nuclear factor erythroid 2-related factor 2 (Nrf2). Furthermore, in metabolic syndrome experimental models, quercetin showed positive effects on left ventricular relaxation by preventing E/A reduction, mediated by enhancing SOD and glutathione peroxidase activity, inducing Nrf2 nuclear translocation, and increasing ATP myocardial levels [118]. In a mouse model of cardiac toxicity induced by doxorubicin [119], where the modulation of oxidative stress activity was mediated by pAkt pathway, ischemia/reperfusion (I/R) experiments revealed that quercetin improves parameters of left ventricular relaxation and contraction. Another investigation focused on the protective role of quercetin on myocardial I/R injury revealed reduction of infarct size and enhanced myocardial contractility and coronary flow. These results were explained by the role of quercetin on inhibiting the nonhistone DNA-binding protein pathway [120]. Peroxisome proliferator-activated receptor $\gamma$ (PPAR- $\gamma$ ) inhibition attenuated the effects of quercetin on ROS production, SOD and glutathione peroxidase activation, suppression of $\mathrm{NF}-\kappa \mathrm{B}$ pathway, and myocardial apoptosis. These modifications suggested that the underlying protective mechanism of quercetin on myocardial injury is related to the inhibition of the NF- $\kappa \mathrm{B}$ pathway by PPAR- $\gamma$ activation. In a study [121], after 10 days of intraperitoneal and oral administration of quercetin, a notable amelioration of LVEF was 
demonstrated. Other molecules similar to quercetin, such as taxifolin, in both in vitro and in vivo experimental models of cardiac hypertrophy, have demonstrated significantly reduced ROS production and phosphorylation of MAPKactivated protein kinase 2 and attenuated cardiac fibrosis and left ventricular remodeling [122]. It seems that taxifolin in diabetic cardiomyopathy improves diastolic dysfunction by reducing angiotensin II levels, inhibiting NADPH oxidase activity and inducing JAK/STAT3 activity [123]. The abovementioned results suggest that in HFpEF quercetin and similar molecules may improve left ventricular relaxation at least in part by modulating oxidative stress response which in turn influences cardiac remodeling development. Then, the study of the therapy with quercetin and similar molecules in combination with well-known drugs, as ACE inhibitors/sartans, beta blockers or other modulators of adrenergic system activity, in experimental models of HFrEF would be of interest.

3.3.2. Resveratrol. Resveratrol is a stilbene present in grapes, blueberries, and peanuts produced when plants undergo infections or ultraviolet radiation. Based on the beneficial cardiovascular effect of red wine consumption, many interesting studies [124-126] have investigated the protective mechanism of resveratrol against endothelial dysfunction and myocardial tissue injury. In endothelial cells culture, isolated by bovine aortic rings cultured, red wine extracts increased the intracellular Ca2+ level, enhanced eNOS activity and, as a final result, attenuated NO release [127]. Further studies showed that red wine polyphenols are responsible for the phosphorylation of Akt and eNOS which in turn activate NO release. However, in the presence of PI3 inhibitors, polyphenols failed to induce vasorelaxation, suggesting that the PI3-kinase/Akt pathway is crucial [128]. Both resveratrol pretreatment and treatment in ischemia/reperfusion (I/R) injury has shown to reduce the generation of ROS, to scavenge ROS and to modulate the activity of SOD $[129,130]$.

Activation of SOD and glutathione peroxidase and reduction of proinflammatory biomarkers as myeloperoxidase by resveratrol were correlated to the activation Nrf2/ARE pathway [131]. Other data indicate that resveratrol reduced the production of TNF- $\alpha$, attenuated the expression of TLR $4 / N F-\kappa B$ in the ischemic area, and enhanced the synthesis of NO. Of note, application of sNO inhibitors abolished the positive effects of resveratrol [132]. Moreover, resveratrol significantly improves left ventricular-developed pressure and aortic flow and reduces infarct size area, with a significant amelioration of LVEF [131]. Of interest, a recent meta-analysis performed on preclinical studies concluded that in small animal models of I/R injury resveratrol significantly improves infarct size and the benefits were not affected by the duration of reperfusion [133]. Other pathways involved in the modification of the oxidative stress pathway by resveratrol seems to be attributed to MAPK signaling, Sirt 1 and Sirt 3 activation, and FoxO/NAD activity. Indeed, experiments [134] have demonstrated that resveratrol induced upregulation of Sirt1 expression and downregulation of FoxO1 and these modifications were associated with restoration of the severe diastolic impairment, inhibition of iron-induced profibrotic effect, and increased expression of myocardial SERCA2 protein. Importantly, the examination of $\mathrm{Ca} 2+$ homeostasis, in cardiomyocytes isolated from early iron-overloaded mice, demonstrated elevated diastolic $\mathrm{Ca} 2+$ levels and prolongation of $\mathrm{Ca} 2+$ decay. These changes were corrected by in vivo SERCA2a gene therapy and resveratrol [134]. The modifications in Sirt1 signaling and oxidative stress response were described also in doxorubicin-induced cardiotoxicity, where resveratrol upregulated the expression of Sirt1 protein by attenuating the acetylation of $\mathrm{p} 53$ protein [135]. Other associated findings were reduction of myocardial apoptosis, alleviation of oxidative stress, and reduction of left ventricular end-diastolic pressure [135]. Similar results regarding components of reactive cardiac fibrosis, such as cardiomyocyte apoptosis and collagen accumulation in the extracellular matrix of myocardial tissue, were reported in pressure overload-induced hypertrophy [136]. It should be mentioned that resveratrol can attenuate the transition of cardiac fibroblasts phenotype in myofibroblasts acting through TGF $\beta$-Smad3 signaling and inhibiting ROS/ERK/TGF $\beta /$ periostin pathway [137]. Riba et al. [126] recently reported that resveratrol treatment showed a protective effect on oxidative stress as indicated by the reduction of iNOS, COX-2 activity, ROS generation. Regarding left ventricular dysfunction, resveratrol-treated rats increased LVEF and reduced left ventricular mass. These beneficial effects were associated with the interaction of resveratrol with cellular survival (e.g., Akt-1, GSK-3 $\beta$ ) and stress signaling pathways (e.g., p38-MAPK, ERK 1/2, MKP-1) [126, 133]. Therefore, resveratrol administration seems to have high potentials regarding restoration of left ventricular relaxation and reduction of myocardial apoptosis and infarct size area in HF models. The modulation of oxidative stress response appears cardinal. However, further investigation regarding survival and in-depth signaling pathway interactions are necessary.

3.3.3. Curcumin. Curcumin is a polyphenol found in turmeric plants which exhibits anti-inflammatory, antioxidant, and antifibrotic properties. Several studies have tested the hypothesis of a possible cardioprotective role of this compound [138].

Curcumin showed to be effective in inhibiting maladaptive cardiac remodeling and preserving cardiac function after I/R injury. In particular, Wang et al. [139] demonstrated that, after oral administration of curcumin during reperfusion, collagen synthesis was reduced and the expression of TGF $\beta 1$ and phospho-Smad2/3 was downregulated. Moreover, stroke volume, LVEF, and left ventricular enddiastolic volume were significantly improved. Toll-like receptor-2 (TLR2) inhibition by curcumin was also described in I/R experiments, and this effect was associated with preservation of cardiac contractility [140]. It has been proposed that the cardioprotective role of curcumin against myocardial injury is related to the activation of JAK2/STAT3 signaling pathway [141]. Other pathways related to curcumin effects in HF are the modulation of AT1/AT2 receptors and $\mathrm{NF}-\kappa \mathrm{B}[142,143]$. It is also reported that curcumin-reduced acetylation has a beneficial effect against myocardial injury [144]. 
Curcumin pretreatment in myocardial infarction models induced by left coronary artery ligation attenuated the expression of Sirt1 and reduced collagen deposition. In vitro experiments revealed that the genetic inhibition of Sirt1 by small interfering molecules blocked the effects of curcumin on cardiac fibroblast proliferation and migration [145]. It has been suggested that curcumin cardioprotective role is also related to Sirtl-dependent activation of eNOS. Indeed, in vitro treatment of endothelial cells with curcumin, protected against premature senescence, increased the Sirtl activation and reduced the production of ROS [146]. Curcumin administration of $5 \mathrm{mg} / \mathrm{kg} /$ day and $50 \mathrm{mg} / \mathrm{kg} /$ day during 6 weeks in myocardial infarction experimental model resulted in a significant dose-dependent improvement of left ventricular fractional shortening [147]. Recently, the use of curcumin nanoparticles showed promising results regarding cardiac remodeling and antioxidative and anti-inflammatory properties in isoproterenol-induced myocardial infarction model [148]. Therefore, nanotechnology curcumin delivery may be a future application in HF experimental and clinical models. Table 1 summarizes the abovementioned studies, describing molecular modifications and phytochemical effects on the cardiovascular system.

3.4. Polyphenols and HF in Humans. Despite the preclinical studies reporting excellent results of quercetin, curcumin, and resveratrol on infarct size reduction, diastolic function, and cardiac remodeling, the application of these compounds in clinical HF models is limited. Quercetin administration in hypertensive and obese patients initially reported some positive effects in blood pressure control without showing any modulation of oxidative stress or endothelial function [149, 150]. However, other studies failed to show similar results. A recent study reports that quercetin administration for 12 months in patients with gout and hypertension, normalized the blood pressure control and improved left ventricular diastolic function [151]. In a randomized study [152] on patients with stable angina under optimal drug therapy, $120 \mathrm{mg}$ twice/day of quercetin reported amelioration of left ventricular systolic and diastolic function, with a reduction in the circulatory level of proinflammatory cytokines as IL- $1 \beta$, TNF- $\alpha$, and NF- $\kappa$ B [153]. In patients undergoing [154] CABG surgery, the incidence of in-hospital myocardial infarction was decreased from $30.0 \%$ in the placebo group to $13.1 \%$ in the group treated with $4 \mathrm{~g} /$ day of curcuminoid (adjusted hazard ratio $0.35,0.13$ to $0.95, p=0.038$ ) and postoperative $\mathrm{C}$-reactive protein; N-terminal pro-Btype natriuretic peptide levels were also lower in the curcuminoid than in the placebo group. It should be mentioned that the incidence of drug-related adverse events was not different between the placebo and curcuminoid groups, and gastrointestinal symptoms were the main drug-related adverse events.

Although the administration of resveratrol has revealed beneficial anti-inflammatory effects and amelioration of blood pressure control in a different population, no data are available on its effects on left ventricular relaxation or diastolic function [155]. A triple-blind placebo control trial [156], investigating the role of resveratrol and magnesium stearate administration, did not find inflammatory profile reduction. Participants were randomized in homogenous groups for age, gender, comorbidities, cardiovascular risk factor, and LVEF. This study also did not describe changes in diastolic function after resveratrol therapy [156]. In contrast, Milatrau et al. [157] describe not only a reduction of triglycerides and total cholesterol level but also less angina pectoris episodes during and after a short-term follow-up, with a significant reduction of NT-proBNP levels after resveratrol therapy, that could suggest an amelioration of left ventricular function.

Some studies suggest that resveratrol may have an impact on myocardial function in HF patients. Resveratrol administration in a population of myocardial infarction patients [158] resulted in improvement of left ventricular diastolic function, endothelial function measured by flow-mediated vasodilatation, and LDL cholesterol, without improvement in LVEF. Indeed, a positive trend in LVEF amelioration was assessed without achieving a statistical significance (mean LVEF at baseline and after 3-month treatment with $10 \mathrm{mg}$ of resveratrol in placebo and resveratrol group were respectively $52.42 \pm 1.55 \%, 51.33 \pm 1.84 \%$ and $54.77 \pm 1.64 \%$, $55.83 \pm 1.94 \%)$. Another randomized placebo-controlled study [159], on the effect of flavanol-rich chocolate in HF patients, reported an improvement of endothelial function and inhibition of platelet activation in HF patients. In Table 2, we report studies focused on the phytochemicals use in human HF models.

By these results, it could be speculated that polyphenols might have a more pronounced role in HFpEF than HFrEF. However, in complex, investigation of polyphenol efficacy in patients with cardiovascular disease or cardiovascular risk factors has not reported the same fascinating results as in experimental models. The most updated metaanalysis on this topic [160], in fact, reports that there is no significant amelioration of the lipid, atherosclerotic, and glycemic profile and no significant reduction of blood pressure. It should be mentioned that these studies are characterized by important limitations, as small sample sizes, differences in doses, and protocols. Second, the structural and physiological differences between polyphenols make challenging their short- and long-term health effects. Third, different metabolism of polyphenols can differently affect physiological functions, producing high interindividual differences in the biological response. Indeed, pharmacokinetic studies of polyphenols on humans are very few. Moreover, biotransformation of polyphenols is still debatable and should be considered that drug-metabolizing enzymes in phase I, II, and III represent potential sites of interactions between drugs and polyphenols.

3.5. Phytosterols. Phytosterols are bioactive components of plant origin, not synthesized in the human body, that regulate the membrane fluidity of plant cells. The main food sources for phytosterols are vegetable oils, nuts, and cereals. Based on their chemical structure, they are classified in plant sterols and plant stanols. Plant sterols are distinctive for the presence of a double bond in the sterol ring and the most studied sterols are campesterol, sitosterol, and stigmasterol. 


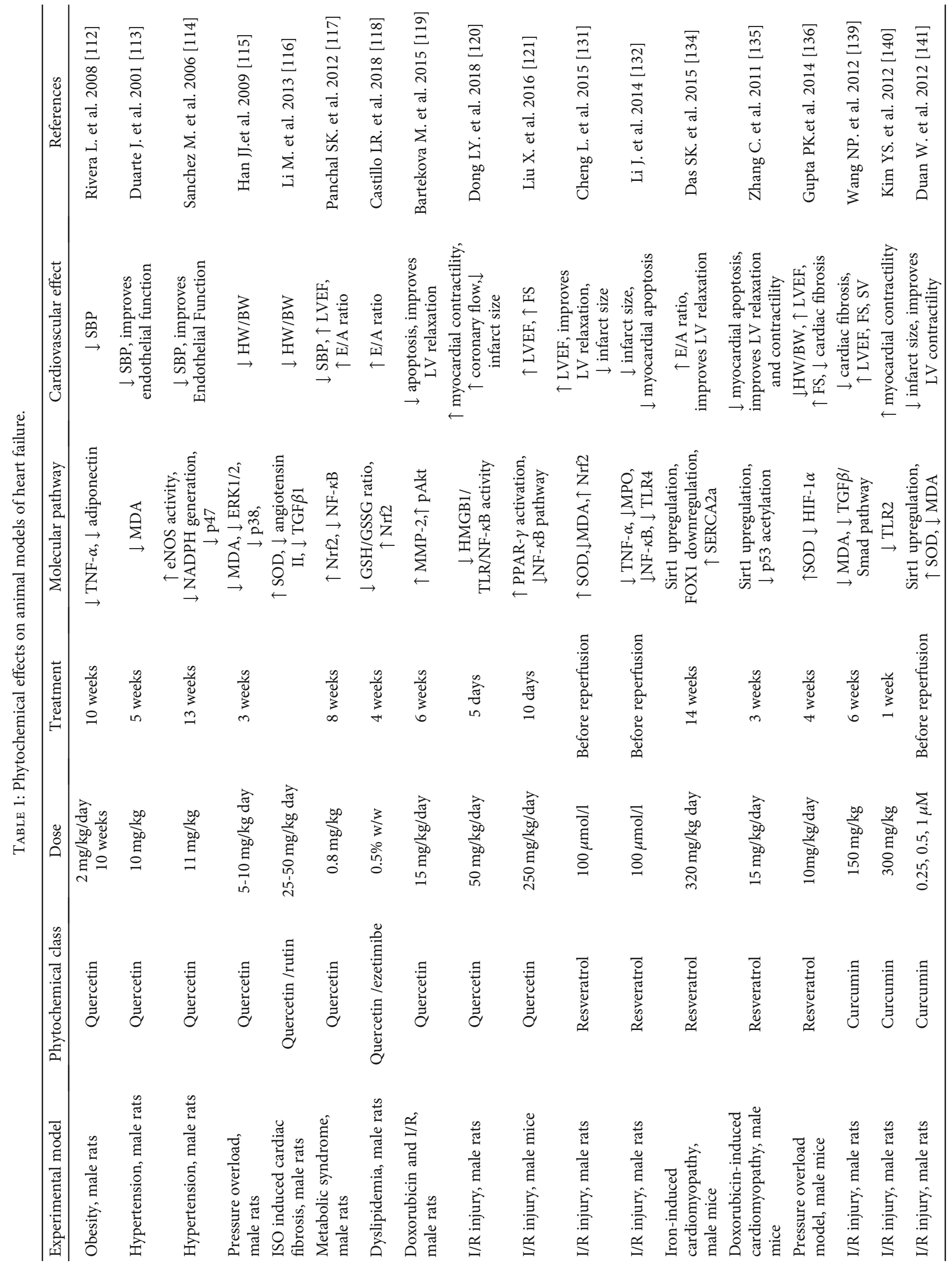




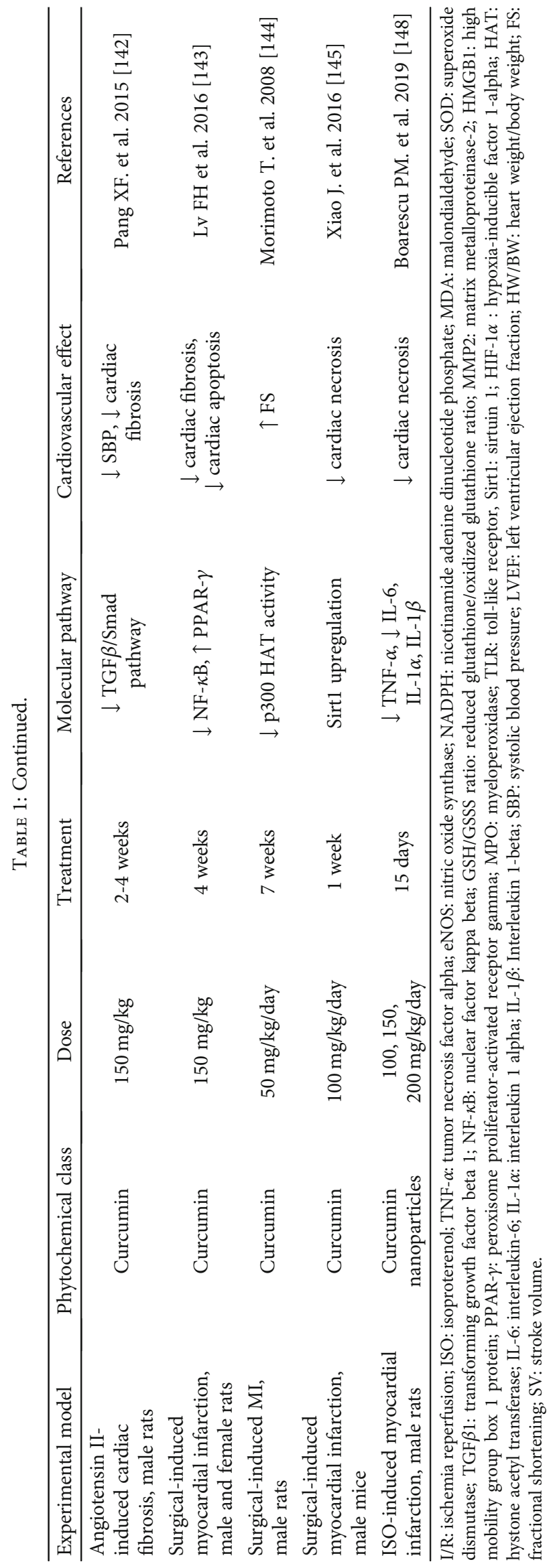







While examples of plant stanols are campestanol and sitostanol. About $0.5 \%$ of dietary plant stanols and 5\% of dietary plant sterols are systemically absorbed [161]. In brief, the absorption process includes their incorporation into mixed micelles, transportation from the intestinal lumen to enterocytes mediated by Niemann Pick C1 Like 1 (NPC1L) protein, and phytosterols secretion into the intestinal lumen mediated by efflux transporters as ATPbinding cassette (ABC) proteins known as ABCG5 and ABCG8 [162].

The speculation with regard to a potential deleterious effect of phytosterols has been largely motivated by the fact that phytosterolemia, a rare autosomal recessive disease, is characterized by a 50 -fold increased circulating concentration of plant sterols and may be associated with early atherosclerosis [163]. Several studies have evaluated the association between plasma phytosterol concentration and CVD; however, the results are conflicting. Dietary phytosterol intake increases plasma levels, but increased plasma phytosterols are believed to be a coronary heart disease risk factor. Epidemiological studies have suggested either a direct association between plasma phytosterols and coronary heart disease risk [164] or a null $[165,166]$ and even inverse association [167]. In the prospective cohort of the Spanish EPIC study [168], plasma concentrations of the main phytosterols, sitosterol, and campesterol appear to be markers of a lower cardiometabolic risk. The study suggests that moderately elevated plasma sitosterol, but not campesterol, might signal individuals with a reduced risk for CHD. However, the authors concluded that they cannot answer the important question of whether circulating phytosterols are proatherogenic, antiatherogenic, or neutral.

Genser et al. [169] published a systematic review and meta-analysis based on 17 studies involving 11,182 individuals and found no evidence of an association between serum concentration of phytosterols and the development of CVD. The authors of this meta-analysis attributed the great divergence in the results of the studies to the different designs of studies and adjustments for potential confounding variables. The results in the study were conflicting because most of them do not take into account potential confounding variables and are provided in different study designs.

Different studies [170-174] have investigated the role of phytosterols on endothelial function and inflammatory profile. Similarly, the arterial stiffness and the flowmediated dilatation were not modified in hypercholesterolemia or hypercholesterolemia and diabetes [170, 171]. Nonetheless, Gylling et al. [172] have reported beneficial effects on endothelial function and arterial stiffness. Other authors relate the restore of endothelial function to the modification of biomarkers such as E-selectin and plasminogen activator inhibitor 1 (PAI-1) $[143,173]$. However, in a setting of dyslipidemic patients, either modification of inflammatory profile or endothelial function was not observed. Again, a meta-analysis study failed to show a modification of the inflammatory biomarkers as mainly Creactive protein (CRP), after regular intake of phytosterols [174]. Limited data investigated the role of phytosterols on oxidative stress and modification of ROS release after phytos- terol consumption. A recently published meta-analysis [175] evaluated the effects of phytosterol consumption in plasma concentrations of liposoluble vitamins and carotenoids. It included 41 randomized clinical trials $(n=3,306)$ with a mean phytosterol intake of $2.5 \mathrm{~g} /$ day. In the analyses adjusted for total cholesterol, there was a significant reduction in the concentration of hydrocarbon carotenoids ( $\beta$-carotene, $\alpha$ carotene, and lycopene) and some oxygenated carotenoids (zeaxanthin and cryptoxanthin). In contrast, there was no significant reduction in the concentration of tocopherol, vitamin D, or retinol. A very important finding of this metaanalysis was that the concentration of these substances remained within the normal range, not indicating that the observed reductions could have negative health implications [175]. Yoshida et al. [176] investigated the antioxidant effects of phytosterol and its components, beta-sitosterol, stigmasterol, and campesterol, against lipid peroxidation. It was found that these compounds exerted antioxidant effects on the oxidation of methyl linoleate in solution. Taken together, the findings of the present study showed that phytosterol chemically acts as an antioxidant, a modest radical scavenger, and physically as a stabilizer in the membranes [176]. It is rational to think that lowering the LDL cholesterol level, as one of the major cardiovascular risk factors, may directly influence the risk of developing coronary heart disease and, as a consequence, may reduce the risk from cardiovascular events. However, it should be underlined that studies evaluating the impact of phytosterols and phytostanols on cardiovascular outcome and possible relationship with $\mathrm{HF}$ pathophysiology are lacking.

Prospective cohort studies support the beneficial impact of plant-based dietary patterns on incident HF [177-179]. In a study of 38,075 Finnish people over a median of 14.1 years, higher consumption of vegetables was associated with a lower incidence of HF in men, but not in women [180]. Similarly, among 20,900 healthy male physicians in the Physicians' Health Study I, a greater consumption of fruits and vegetables was associated with a decreased risk of $\mathrm{HF}$ [181]. In a subset of the Reasons for Geographic and Racial Differences in Stroke (REGARDS) Cohort of 15,569 persons with no coronary artery disease or HF diagnosis patients with closer adherence to the plant-based dietary pattern had a lower risk of incident HF [179]. In a prospective cohort from Sweden of 34,319 women without cardiovascular disease and cancer at initial assessment, after 12.9 years, greater fruit and vegetable consumption was associated with a lower rate of $\mathrm{HF}$ [178]. It is hypothesized that HFpEF may be secondary, in part, to diffuse endothelial dysfunction, including that of the myocardial microvasculature, due partly, to increased inflammation [182]. Many plant-based foods are anti-inflammatory and increase NO bioavailability [183], thereby improving vascular health and potentially ameliorating this microvascular dysfunction. The Dietary Approach to Stop Hypertension in "Diastolic" Heart Failure (DASH-DHF) pilot study evaluated the impact of a DASH diet on 13 postmenopausal women with diastolic HF. After 3 weeks, consuming the DASH diet was associated with significant improvements in blood pressure, arterial elasticity, and oxidative stress [184]. 


\section{Dietary Phytochemicals and Sex-Gender}

As discussed in the previous paragraphs, the redox state and oxidative stress response vary between female and male individuals. It is therefore not surprising that such variability involves also the effects produced by the phytochemicals in them.

This largely depends on the differences existing between women and men in the adsorption, distribution, metabolism, and elimination (i.e., pharmacokinetics) and in the pharmacodynamics of the xenobiotics [185].

In particular, phenolic compounds undergo important processes of storage, transport, and biotransformation [186]. The latter is very important considering that female and male subjects have a different amount of CYP450 isoenzymes and molecules controlling their activity (e.g., constitutive androstane receptor (CAR) expression is greater in women than in men). Also, polymorphisms in some CYP450 genes are associated with variable levels of their products [186]. The sexgender-based dissimilarities regard also the enzymes belonging to the phase II of metabolism, and this is reasonable for the phytochemicals, largely metabolized by such proteins including UDP-glucuronosyltransferases (UGTs) and sulfatases (SULTs). Then, the renal elimination of the conjugated phenolic compounds is lower in women compared to men [185].

The differences in the kinetics processes might lead to variability in the effects of all xenobiotics, including dietary phytochemicals. However, the data are still scarce in humans in whom the awareness of the method of action of the drugs, as well as of the natural products, is very important given the potential consequences in the treatment and management of several chronic diseases.

Analyzing the results of the Rotterdam study on the protective effects of quercetin against atherosclerosis, some authors [187] proposed that the better response showed by women could be dependent on a better adsorption of quercetin from rutin. This hypothesis was different from that of the Rotterdam study authors who suggested that the higher benefits could be dependent on the women's estrogen activity [188]. Erlund et al. [189] performed a diet-controlled, double-blind, cross-over study to assess the pharmacokinetics of quercetin in healthy volunteers using doses similar to those derivable from the diet. The evaluation in seven women and nine men revealed that quercetin from rutin but not from aglycone was much more bioavailable in women than in men, particularly in those assuming oral contraceptives.

Not only quercetin but also other (poly)phenolic compounds, such as curcumin and resveratrol, seem to have cardiovascular beneficial effects. However, the strongest evidence has been produced in animal models, while in humans the data are still inconclusive [190].

Curcumin has been suggested to improve vascular endothelial function. In this regard, Santos-Parker et al. [191] recently showed that a 12-week curcumin supplementation is able to increase NO bioavailability and decrease oxidative stress thereby improving both resistance and conduit artery endothelial function in healthy middle-aged and older adults. Notably, the authors reported improvements in both sex-genders but at a greater extent in men compared to women [191].

Resveratrol is one of the most studied phytochemicals because of its potential beneficial effects on several pathologies, including CVD. However, contrasting results have been found. As for other molecules, this could be explained by the numerous factors that potentially influence the resveratrol efficacy and tolerability in humans, such as age, lifestyle, dose, administration medium, gut microbiota, and gender. The latter, as well as the other variables, have not yet been sufficiently investigated [192].

A recent meta-analysis, including 18 randomized trials performed in humans, aimed to clarify whether flavonol supplementation could be useful to reduce biomarkers of CVD risk. The main result was that flavonol consumption improved lipid profile, plasma glucose, and blood pressure but in a variable manner, is strongly dependent on individuals' genetic background and health status. Notably, 9 out of 18 trials included both women and men but most of them did not make a sex-gender-based distinction of the results [193].

In women affected by diabetes mellitus type II, chronic supplementation with quercetin significantly reduced systolic blood pressure [194]. Soy product intake was associated with a reduction of diastolic blood pressure in peri- and postmenopausal women and men [195]. Although both in men and women with mild to moderate hypertension soy products reduced blood pressure [196], the incidence of hypertension was lower among men consuming olive oil [197]. Globally, the above data suggest a plausible sex-gender polyphenol effect on endothelial function.

Ostertag et al. investigated the effects of an acute administration of flavan-3-oil-enriched dark chocolate, one of the bioactive compounds contained in the dark chocolate. By analyzing blood and urine samples of both women and men, the authors found that this flavonol exerted beneficial effects in both sex-genders in a different way. In men, flavan-3-oil-enriched dark chocolate significantly decreased P-selectin expression and adenosine diphosphate-induced platelet aggregation, while, in women, decreased thrombin receptor-activating peptide-induced platelet aggregation and increased thrombin receptoractivating peptide-induced fibrinogen binding. Increased collagen/epinephrine-induced ex vivo bleeding time was observed in both men and women. White chocolate significantly decreased adenosine diphosphate-induced platelet Pselectin expression and increased collagen/epinephrineinduced ex vivo bleeding time only in men [198]. In a prospective cohort study, aimed at assessing the CVD mortality in the US population with a different intake of flavonoids, no significant sex-gender-based heterogeneity in the results was observed. However, when the authors analyzed the data separately in men and women, they found that flavone consumption was associated with a lower risk of fatal ischemic heart disease especially among women and with a lower risk of fatal stroke in men [199].

The impact of sex-gender in the cholesterol-lowering effects exerted by phytosterols also represents a debated issue. Some studies found no differences, while others [200] 
suggested a possible effect of such phytochemicals in reducing LDL-C levels in men but not in women.

It is important to note that, until now, the clinical studies aimed at investigating the effects of phytochemicals by sex-gender are small-scale studies; thus, they are not powered enough to give a conclusive response to a so complex question.

\section{Dietary Phytochemicals, Sex-Gender, and HF}

As previously discussed, the different promising studies suggest a protective role of different phytochemical on heart function. In isolated guinea pig myocytes, polyphenols seem to act differently on intracellular Ca2+ signaling in male and female cells. Lew et al. [201] found fundamental sex differences in the acute actions of the widely consumed isoflavone genistein in guinea pig ventricular myocytes. These differences result in an overall increase in contraction of male myocytes, but little or no change in females. Although genistein inhibited L-type Ca2+ currents in cardiac myocytes from both male and female guinea pigs, a greater percentage inhibition in females was found, suggesting consequent greater cardioprotection of this phytochemical in females than in males.

Stauffer et al. [202] reported that male mice with hypertrophic cardiomyopathy that were fed the traditional soy-based diet deteriorate to severe, dilated cardiomyopathy and more fibrosis, induction of beta-myosin heavy chain, inactivation of glycogen synthase kinase-3beta, and activation of caspase-3. However, simply changing the diet to a milk-based (no soy) diet prevents these phenotypes [202]. Female mice with hypertrophic cardiomyopathy did not exhibit clinical signs of severe cardiac disease on the soy diet, and they were not significantly affected by the dietary change, supporting the hypothesis that in HF some phytochemicals can act in a different sex-oriented way.

Another in vivo study [203] performed on transgenic alpha-myosin heavy chain gene usually fed with polyphenols showed that while female mice increased their cardiac mass and preserved cardiac contractile function; male mice developed thin ventricular walls and had poorly contractile hearts, suggesting a possible role in HF prevention.

However, in all clinical studies, the influence of sexgender in HF prevention and therapy was not fully studied. In a randomized control trial [157] performed on patients with stable angina undergone to administration with calcium-fructoborate and resveratrol, after 2 months, a significant reduction in BNP levels and inflammatory markers, like PCR, was observed. Of interest, males and females were included in this study but an interaction between gender and BNP or inflammatory response to resveratrol level was not performed. Similarly, in other studies [158, 159], although resveratrol improved the endothelial function measured by brachial artery flow dilatation and the inflammatory profile and the E/A ratio in HF patients, the sexgender influence was not taken into account as a confounding variable [159].

\section{Conclusions}

While a large body of evidence supports an association between oxidative stress and $\mathrm{HF}$, and phytochemicals are characterized by important antioxidant properties, until now only a few studies were able to demonstrate some beneficial effects of phytochemicals in HF patients. Scavenging of ROS with antioxidants has proved to not affect in modifying patients' prognosis. Surely one of the main problems in the definition of the phytochemicals' efficacy is related to the sex-gender influence. The still unknown different response to the oxidative stress in women and men surely condition the response to phytochemicals administration, especially in HF subjects. Therefore, further studies are needed to better clarify the possible effects of phytochemicals in HF subjects, taking into account the different sex-gender antioxidant response.

\section{Conflicts of Interest}

The authors declare that there is no conflict of interest regarding the publication of this paper.

\section{Authors' Contributions}

Klara Komici and Valeria Conti equally contributed to this work.

\section{References}

[1] D. Mozaffarian, E. J. Benjamin, A. S. Go et al., "Heart disease and stroke statistics-2015 update: a report from the American Heart Association," Circulation, vol. 131, no. 4, pp. e29-322, 2015.

[2] A. Cannavo, K. Komici, L. Bencivenga et al., "GRK2 as a therapeutic target for heart failure," Expert Opinion on Therapeutic Targets, vol. 22, no. 1, pp. 75-83, 2018.

[3] K. Komici, G. D. Femminella, C. de Lucia et al., "Predisposing factors to heart failure in diabetic nephropathy: a look at the sympathetic nervous system hyperactivity," Aging Clinical and Experimental Research, vol. 31, no. 3, pp. 321-330, 2019.

[4] N. Ferrara, P. Abete, G. Corbi et al., "Insulin-induced changes in beta-adrenergic response: an experimental study in the isolated rat papillary muscle," American Journal of Hypertension, vol. 18, no. 3, pp. 348-353, 2005.

[5] G. Russomanno, G. Corbi, V. Manzo et al., "The anti-ageing molecule sirt1 mediates beneficial effects of cardiac rehabilitation," Immunity \& Ageing, vol. 14, no. 1, p. 7, 2017.

[6] A. Sharma, G. C. Fonarow, J. Butler, J. A. Ezekowitz, and G. M. Felker, "Coenzyme Q10 and heart failure: a state-ofthe-art review," Circulation: Heart Failure, vol. 9, no. 4, article e002639, 2016.

[7] G. Corbi, G. Gambassi, G. Pagano et al., "Impact of an innovative educational strategy on medication appropriate use and length of stay in elderly patients," Medicine, vol. 94, no. 24, article e918, 2015.

[8] F. Franconi, I. Campesi, D. Colombo, and P. Antonini, "Sexgender variable: methodological recommendations for increasing scientific value of clinical studies," Cells, vol. 8, no. 5 , p. $476,2019$. 
[9] A. L. Bui, T. B. Horwich, and G. C. Fonarow, "Epidemiology and risk profile of heart failure," Nature Reviews Cardiology, vol. 8, no. 1, pp. 30-41, 2011.

[10] J. P. Hellermann, S. J. Jacobsen, G. S. Reeder, F. Lopez-Jimenez, S. A. Weston, and V. L. Roger, "Heart failure after myocardial infarction: prevalence of preserved left ventricular systolic function in the community," American Heart Journal, vol. 145, no. 4, pp. 742-748, 2003.

[11] C. de Lucia, G. D. Femminella, G. Rengo et al., "Risk of acute myocardial infarction after transurethral resection of prostate in elderly," BMC Surgery, vol. 13, Supplement 2, p. S35, 2013.

[12] A. A. Merz and S. Cheng, "Sex differences in cardiovascular ageing," Heart, vol. 102, pp. 825-831, 2016.

[13] C. Gebhard, B. E. Stahli, C. E. Gebhard et al., "Age- and gender dependent left ventricular remodeling," Echocardiography, vol. 30, no. 10, pp. 1143-1150, 2013.

[14] C. F. Deschepper and B. Llamas, "Hypertensive cardiac remodeling in males and females," Hypertension, vol. 49, no. 3, pp. 401-407, 2007.

[15] A. Levinsson, M. P. Dubé, J. C. Tardif, and S. de Denus, "Sex, drugs, and heart failure: a sex-sensitive review of the evidence base behind current heart failure clinical guidelines," ESC Heart Failure, vol. 5, no. 5, pp. 745-754, 2018.

[16] G. Corbi, I. Ambrosino, K. Komici, M. Cellurale, A. Lombardi, and N. Ferrara, "Gender differences in response to therapy for cardiovascular diseases," Current Pharmacogenomics and Personalized Medicine, vol. 15, no. 1, 2017.

[17] J. Ballard-Hernandez and D. Itchhaporia, "Heart failure in women due to hypertensive heart disease," Heart Failure Clinics, vol. 15, no. 4, pp. 497-507, 2019.

[18] A. Deswal and B. Bozkurt, "Comparison of morbidity in women versus men with heart failure and preserved ejection fraction," The American Journal of Cardiology, vol. 97, no. 8, pp. 1228-1231, 2006.

[19] F. S. Loffredo, A. P. Nikolova, J. R. Pancoast, and R. T. Lee, "Heart failure with preserved ejection fraction: molecular pathways of the aging myocardium," Circulation Research, vol. 115, no. 1, pp. 97-107, 2014.

[20] G. De Simone, R. B. Devereux, M. Chinali et al., "Sex differences in obesity-related changes in left ventricular morphology: the Strong Heart Study," Journal of Hypertension, vol. 29, no. 7, pp. 1431-1438, 2011.

[21] S. Meyer, P. van der Meer, B. M. Massie et al., "Sex-specific acute heart failure phenotypes and outcomes from PROTECT," European Journal of Heart Failure, vol. 15, no. 12, pp. 1374-1381, 2013.

[22] C. Franssen, S. Chen, A. Unger et al., "Myocardial microvascular inflammatory endothelial activation in heart failure with preserved ejection fraction," JACC: Heart Failure, vol. 4, no. 4, pp. 312-324, 2016.

[23] S. F. Mohammed, S. Hussain, S. A. Mirzoyev, W. D. Edwards, J. J. Maleszewski, and M. M. Redfield, "Coronary microvascular rarefaction and myocardial fibrosis in heart failure with preserved ejection fraction," Circulation, vol. 131, no. 6, pp. 550-559, 2015.

[24] D. Westermann, D. Lindner, M. Kasner et al., "Cardiac inflammation contributes to changes in the extracellular matrix in patients with heart failure and normal ejection fraction," Circulation: Heart Failure, vol. 4, no. 1, pp. 44-52, 2011.
[25] B. W. Florijn, R. Bijkerk, E. P. van der Veer, and A. J. van Zonneveld, "Gender and cardiovascular disease: are sexbiased microRNA networks a driving force behind heart failure with preserved ejection fraction in women?," Cardiovascular Research, vol. 114, no. 2, pp. 210-225, 2018.

[26] F. J. Giordano, "Oxygen, oxidative stress, hypoxia, and heart failure," The Journal of Clinical Investigation, vol. 115, no. 3, pp. 500-508, 2005.

[27] V. Conti, M. Forte, G. Corbi et al., "Sirtuins: possible clinical implications in cardio and cerebrovascular diseases," Current Drug Targets, vol. 18, no. 4, pp. 473-484, 2017.

[28] H. Tsutsui, S. Kinugawa, and S. Matsushima, "Oxidative stress and heart failure," American Journal of Physiology Heart and Circulatory Physiology, vol. 301, no. 6, pp. H2181-H2190, 2011.

[29] V. Conti, G. Corbi, V. Manzo, G. Pelaia, A. Filippelli, and A. Vatrella, "Sirtuin 1 and aging theory for chronic obstructive pulmonary disease," Analytical Cellular Pathology, vol. 2015, Article ID 897327, 8 pages, 2015.

[30] S. G. Rhee, "Redox signaling: hydrogen peroxide as intracellular messenger," Experimental \& Molecular Medicine, vol. 31, no. 2, pp. 53-59, 1999.

[31] T. Ide, H. Tsutsui, S. Kinugawa et al., "Mitochondrial electron transport complex $i$ is a potential source of oxygen free radicals in the failing myocardium," Circulation Research, vol. 85, no. 4, pp. 357-363, 1999.

[32] T. Ide, H. Tsutsui, S. Kinugawa et al., "Direct evidence for increased hydroxyl radicals originating from superoxide in the failing myocardium," Circulation Research, vol. 86, no. 2, pp. 152-157, 2000.

[33] M. F. Hill and P. K. Singal, "Antioxidant and oxidative stress changes during heart failure subsequent to myocardial infarction in rats," The American Journal of Pathology, vol. 148, no. 1, pp. 291-300, 1996.

[34] Z. Mallat, I. Philip, M. Lebret, D. Chatel, J. Maclouf, and A. Tedgui, "Elevated levels of 8-iso-prostaglandin $\mathrm{F}_{2 \alpha}$ in pericardial fluid of patients with heart failure: a potential role for in vivo oxidant stress in ventricular dilatation and progression to heart failure," Circulation, vol. 97, no. 16, pp. 15361539, 1998.

[35] S. S. Signorelli, M. Anzaldi, M. Libra et al., "Plasma levels of inflammatory biomarkers in peripheral arterial disease: results of a cohort study," Angiology, vol. 67, no. 9, pp. 870874, 2016.

[36] T. Ide, H. Tsutsui, S. Hayashidani et al., "Mitochondrial DNA damage and dysfunction Associated with oxidative stress in failing hearts after myocardial infarction," Circulation Research, vol. 88, no. 5, pp. 529-535, 2001.

[37] I. A. Hobai and B. O’Rourke, "Enhanced $\mathrm{Ca}^{2+}$-activated $\mathrm{Na}^{+}$$\mathrm{Ca}^{2+}$ exchange activity in canine pacing-induced heart failure," Circulation Research, vol. 87, no. 8, pp. 690-698, 2000.

[38] M. Kohlhaas, T. Liu, A. Knopp et al., "Elevated cytosolic $\mathrm{Na}^{+}$ increases mitochondrial formation of reactive oxygen species in failing cardiac myocytes," Circulation, vol. 121, pp. 1606$1613,2010$.

[39] J. M. Li, N. P. Gall, D. J. Grieve, M. Chen, and A. M. Shah, "Activation of NADPH oxidase during progression of cardiac hypertrophy to failure," Hypertension, vol. 40, no. 4, pp. 477484, 2002.

[40] C. Doerries, K. Grote, D. Hilfiker-Kleiner et al., "Critical role of the $\mathrm{NAD}(\mathrm{P}) \mathrm{H}$ oxidase subunit $\mathrm{p} 47^{\text {phox }}$ for left ventricular 
remodeling/dysfunction and survival after myocardial infarction," Circulation Research, vol. 100, no. 6, pp. 894-903, 2007.

[41] J. Kuroda, T. Ago, S. Matsushima, P. Zhai, M. D. Schneider, and J. Sadoshima, "NADPH oxidase 4 (Nox4) is a major source of oxidative stress in the failing heart," Proceedings of the National Academy of Sciences of the United States of America, vol. 107, no. 35, pp. 15565-15570, 2010.

[42] E. Takimoto, H. C. Champion, M. Li et al., "Oxidant stress from nitric oxide synthase- 3 uncoupling stimulates cardiac pathologic remodeling from chronic pressure load," The Journal of Clinical Investigation, vol. 115, no. 5, pp. 12211231, 2005.

[43] A. K. Doughan, D. G. Harrison, and S. I. Dikalov, "Molecular mechanisms of angiotensin II-mediated mitochondrial dysfunction: linking mitochondrial oxidative damage and vascular endothelial dysfunction," Circulation Research, vol. 102, no. 4, pp. 488-496, 2008.

[44] N. Khaper, K. Kaur, T. Li, F. Farahmand, and P. K. Singal, "Antioxidant enzyme gene expression in congestive heart failure following mycardial infarction," Molecular and Cellular Biochemistry, vol. 251, no. 1-2, pp. 9-15, 2003.

[45] T. Shiomi, H. Tsutsui, H. Matsusaka et al., "Overexpression of glutathione peroxidase prevents left ventricular Remodeling and failure after myocardial infarction in mice," Circulation, vol. 109, no. 4, pp. 544-549, 2004.

[46] T. Yoshida, M. Watanabe, D. T. Engelman et al., "Transgenic mice overexpressing glutathione peroxidase are resistant to myocardial ischemia reperfusion injury," Journal of Molecular and Cellular Cardiology, vol. 28, no. 8, pp. 1759-1767, 1996.

[47] N. Khaper and P. K. Singal, "Effects of afterload-reducing drugs on pathogenesis of antioxidant changes and congestive heart failure in rats," Journal of the American College of Cardiology, vol. 29, no. 4, pp. 856-861, 1997.

[48] N. Khaper, K. Kaur, T. Li, F. Farahmand, and P. K. Singal, "Antioxidant enzyme gene expression in congestive heart failure following myocardial infarction," Molecular and Cellular Biochemistry, vol. 251, no. 1-2, pp. 9-15, 2003.

[49] J. B. Pillai, A. Isbatan, S. Imai, and M. P. Gupta, "Poly(ADPribose) polymerase-1-dependent cardiac myocyte cell death during heart failure is mediated by $\mathrm{NAD}^{+}$Depletion and reduced Sir $2 \alpha$ deacetylase activity," The Journal of Biological Chemistry, vol. 280, no. 52, pp. 43121-43130, 2005.

[50] C. P. Hsu, S. Oka, D. Shao, N. Hariharan, and J. Sadoshima, "Nicotinamide Phosphoribosyltransferase regulates cell survival through $\mathrm{NAD}^{+}$Synthesis in cardiac myocytes," Circulation Research, vol. 105, no. 5, pp. 481-491, 2009.

[51] T. Damy, M. Kirsch, L. Khouzami et al., "Glutathione deficiency in cardiac patients is related to the functional status and structural cardiac abnormalities," PLoS One, vol. 4, no. 3, article e4871, 2009.

[52] H. Tsutsui, T. Ide, S. Hayashidani et al., "Greater susceptibility of failing cardiac myocytes to oxygen free radicalmediated injury," Cardiovascular Research, vol. 49, no. 1, pp. 103-109, 2001.

[53] H. Mollnau, M. Oelze, M. August et al., "Mechanisms of increased vascular superoxide production in an experimental model of idiopathic dilated cardiomyopathy," Arteriosclerosis, Thrombosis, and Vascular Biology, vol. 25, no. 12, pp. 2554-2559, 2005.

[54] A. Schafer, D. Fraccarollo, P. Tas, I. Schmidt, G. Ertl, and J. Bauersachs, "Endothelial dysfunction in congestive heart failure: ACE inhibition vs. angiotensin II antagonism," European Journal of Heart Failure, vol. 6, no. 2, pp. 151-159, 2004.

[55] G. A. Silberman, T. H. Fan, H. Liu et al., "Uncoupled cardiac nitric oxide synthase mediates diastolic dysfunction," Circulation, vol. 121, no. 4, pp. 519-528, 2010.

[56] K. Bhatia, A. A. Elmarakby, A. B. El-Remessey, and J. C. Sullivan, "Oxidative-stress contributes to sex differences in angiotensin II-mediated hypertension in spontaneously hypertensive rats," American Journal of Physiology Regulatory, Integrative and Comparative Physiology, vol. 302, no. 2, pp. R274-R282, 2012.

[57] P. Matarrese, T. Colasanti, B. Ascione et al., "Gender disparity in susceptibility to oxidative stress and Apoptosis Induced by autoantibodies specific to RLIP76 in vascular cells," Antioxidants \& Redox Signaling, vol. 15, no. 11, pp. 2825-2836, 2011.

[58] H. S. Marinho, C. Real, L. Cyrne, H. Soares, and F. Antunes, "Hydrogen peroxide sensing, signaling and regulation of transcription factors," Redox Biology, vol. 2, pp. 535-562, 2014.

[59] R. P. Brandes and A. Mügge, "Gender differences in the generation of superoxide anions in the rat aorta," Life Sciences, vol. 60, pp. 391-396, 1997.

[60] C. Vassalle, R. Sciarrino, S. Bianchi, D. Battaglia, A. Mercuri, and S. Maffei, "Sex-related differences in association of oxidative stress status with coronary artery disease," Fertility and Sterility, vol. 97, no. 2, pp. 414-419.e2, 2012.

[61] Y. Chen, L. L. Ji, T. Y. Liu, and Z. T. Wang, "Evaluation of gender-related differences in various oxidative stress enzymes in mice," The Chinese Journal of Physiology, vol. 54, no. 6, pp. 385-390, 2011.

[62] J. Barp, A. S. Araújo, T. R. G. Fernandes et al., "Myocardial antioxidant and oxidative stress changes due to sex hormones," Brazilian Journal of Medical and Biological Research, vol. 35, no. 9, pp. 1075-1081, 2002.

[63] A. A. Miller, G. R. Drummond, A. E. Mast, H. H. H. W. Schmidt, and C. G. Sobey, "Effect of gender on NADPHoxidase activity, expression, and function in the cerebral circulation: role of estrogen," Stroke, vol. 38, no. 7, pp. 21422149, 2007.

[64] S. Matsushima, J. Kuroda, T. Ago et al., "Broad suppression of NADPH oxidase activity exacerbates ischemia/reperfusion injury through inadvertent downregulation of hypoxiainducible Factor- $1 \alpha$ and upregulation of peroxisome proliferator-activated Receptor- $\alpha$," Circulation Research, vol. 112, no. 8, pp. 1135-1149, 2013.

[65] T. Münzel, T. Gori, J. F. Keaney Jr., C. Maack, and A. Daiber, "Pathophysiological role of oxidative stress in systolic and diastolic heart failure and its therapeutic implications," European Heart Journal, vol. 36, no. 38, pp. 2555-2564, 2015.

[66] P. S. Wong, M. D. Randall, and R. E. Roberts, "Sex differences in the role of NADPH oxidases in endothelium-dependent vasorelaxation in porcine isolated coronary arteries," Vascular Pharmacology, vol. 72, pp. 83-92, 2015.

[67] M. E. Mendelsohn, "Protective effects of estrogen on the cardiovascular system," The American Journal of Cardiology, vol. 89, Supplement 1, pp. 12E-17E, 2002.

[68] A. H. Wagner, M. R. Schroeter, and M. Hecker, " $17 \beta$-estradiol inhibition of NADPH oxidase expression in human endothelial cells," The FASEB Journal, vol. 15, no. 12, pp. 2121-2130, 2001. 
[69] J. R. Nofer, "Estrogens and atherosclerosis: insights from animal models and cell systems," Journal of Molecular Endocrinology, vol. 48, no. 2, pp. R13-R29, 2012.

[70] D. Camper-Kirby, S. Welch, A. Walker et al., "Myocardial Akt activation and gender: increased nuclear activity in females versus males," Circulation Research, vol. 88, no. 10, pp. 1020-1027, 2001.

[71] R. D. Patten, I. Pourati, M. J. Aronovitz et al., " $17 \beta$-estradiol reduces cardiomyocyte apoptosis in vivo and in vitro via activation of phospho-inositide-3 kinase/Akt signaling," Circulation Research, vol. 95, no. 7, pp. 692-699, 2004.

[72] M. Skavdahl, C. Steenbergen, J. Clark et al., "Estrogen receptor- $\beta$ mediates male-female differences in the development of pressure overload hypertrophy," American Journal of Physiology Heart and Circulatory Physiology, vol. 288, no. 2, pp. H469-H476, 2005.

[73] A. Iorga, J. Li, S. Sharma et al., "Rescue of pressure overloadinduced heart failure by estrogen therapy," Journal of the American Heart Association, vol. 5, article e002482, 2016.

[74] T. M. De Silva, B. R. Broughton, G. R. Drummond, C. G. Sobey, and A. A. Miller, "Gender influences cerebral vascular responses to angiotensin II through Nox2-derived reactive oxygen species," Stroke, vol. 40, no. 4, pp. 1091-1097, 2009.

[75] J. P. Pierce, J. Kievits, B. Graustein, R. C. Speth, C. Iadecola, and T. A. Milner, "Sex differences in the subcellular distribution of angiotensin type 1 receptors and NADPH oxidase subunits in the dendrites of $\mathrm{C} 1$ neurons in the rat rostral ventrolateral medulla," Neuroscience, vol. 163, no. 1, pp. 329338, 2009.

[76] A. P. Dantas, M. C. Franco, M. M. Silva-Antonialli et al., "Gender differences in superoxide generation in microvessels of hypertensive rats: role of $\mathrm{NAD}(\mathrm{P}) \mathrm{H}$-oxidase," Cardiovascular Research, vol. 61, no. 1, pp. 22-29, 2004.

[77] R. P. Goncalves, K. L. Guarido, J. Assreuy, and J. E. da SilvaSantos, "Gender-specific differences in the in situ cardiac function of endotoxemic rats detected by pressure-volume catheter," Shock, vol. 42, no. 5, pp. 415-423, 2014.

[78] J. Sun, E. Picht, K. S. Ginsburg, D. M. Bers, C. Steenbergen, and E. Murphy, "Hypercontractile female hearts exhibit increased S-nitrosylation of the L-type $\mathrm{Ca}^{2+}$ channel $\alpha 1$ subunit and reduced ischemia/reperfusion injury," Circulation Research, vol. 98, no. 3, pp. 403-411, 2006.

[79] C. Steenbergen, E. Murphy, L. Levy, and R. E. London, "Elevation in cytosolic free calcium concentration early in myocardial ischemia in perfused rat heart," Circulation Research, vol. 60, no. 5, pp. 700-707, 1987.

[80] H. M. Piper, K. Meuter, and C. Schafer, "Cellular mechanisms of ischemia-reperfusion injury," The Annals of Thoracic Surgery, vol. 75, pp. S644-S648, 2003.

[81] E. Murphy and C. Steenbergen, "Gender-based differences in mechanisms of protection in myocardial ischemia-reperfusion injury," Cardiovascular Research, vol. 75, no. 3, pp. 478-486, 2007.

[82] M. C. Kander, Y. Cui, and Z. Liu, "Gender difference in oxidative stress: a new look at the mechanisms for cardiovascular diseases," Journal of Cellular and Molecular Medicine, vol. 21, no. 5, pp. 1024-1032, 2017.

[83] C. Chen, L. X. Hu, T. Dong et al., "Apoptosis and autophagy contribute to gender difference in cardiac ischemia- reperfusion induced injury in rats," Life Sciences, vol. 93, no. 7, pp. 265-270, 2013.
[84] S. Muralimanoharan, C. Li, E. S. Nakayasu et al., "Sexual dimorphism in the fetal cardiac response to maternal nutrient restriction," Journal of Molecular and Cellular Cardiology, vol. 108, pp. 181-193, 2017.

[85] L. Du, R. W. Hickey, H. Bayir et al., "Starving neurons show sex difference in autophagy," Journal of Biological Chemistry, vol. 284, no. 4, pp. 2383-2396, 2009.

[86] P. Matarrese, P. Tieri, S. Anticoli et al., "X-chromosomelinked miR548am-5p is a key regulator of sex disparity in the susceptibility to mitochondria-mediated apoptosis," Cell Death \& Disease, vol. 10, no. 9, p. 673, 2019.

[87] R. H. Liu, "Potential synergy of phytochemicals in cancer prevention: mechanism of action," The Journal of Nutrition, vol. 134, no. 12, pp. 3479S-3485S, 2004.

[88] G. Corbi, V. Conti, S. Davinelli, G. Scapagnini, A. Filippelli, and N. Ferrara, "Dietary phytochemicals in neuroimmunoaging: a new therapeutic possibility for humans?" Frontiers in Pharmacology, vol. 7, p. 364, 2016.

[89] V. Conti, V. Izzo, G. Corbi et al., "Antioxidant supplementation in the treatment of aging-associated diseases," Frontiers in Pharmacology, vol. 7, p. 24, 2016.

[90] S. Davinelli, A. Trichopoulou, G. Corbi, I. De Vivo, and G. Scapagnini, "The potential nutrigeroprotective role of Mediterranean diet and its functional components on telomere length dynamics," Ageing Research Reviews, vol. 49, pp. 1-10, 2019.

[91] D. Vauzour, A. Rodriguez-Mateos, G. Corona, M. J. OrunaConcha, and J. P. Spencer, "Polyphenols and human health: prevention of disease and mechanisms of action," Nutrients, vol. 2, no. 11, pp. 1106-1131, 2010.

[92] R. Mattera, M. Benvenuto, M. G. Giganti et al., "Effects of polyphenols on oxidative stress-mediated injury in cardiomyocytes," Nutrients, vol. 9, no. 5, p. 523, 2017.

[93] H. Cory, S. Passarelli, J. Szeto, M. Tamez, and J. Mattei, “The role of polyphenols in human health and food systems: a mini-review," Frontiers in Nutrition, vol. 5, p. 87, 2018.

[94] M. Fantini, M. Benvenuto, L. Masuelli et al., "In vitro and in vivo antitumoral effects of combinations of polyphenols, or polyphenols and anticancer drugs: perspectives on cancer treatment," International Journal of Molecular Sciences, vol. 16, no. 12, pp. 9236-9282, 2015.

[95] C. Manach, A. Scalbert, C. Morand, C. Rémésy, and L. Jiménez, "Polyphenols: food sources and bioavailability," The American Journal of Clinical Nutrition, vol. 79, no. 5, pp. 727-747, 2004.

[96] S. Quideau, D. Deffieux, C. Douat-Casassus, and L. Pouysegu, "Plant polyphenols: chemical properties, biological activities, and synthesis," Angewandte Chemie International Edition, vol. 50, no. 3, pp. 586-621, 2011.

[97] S. Davinelli, G. Corbi, S. Righetti et al., "Cardioprotection by cocoa polyphenols and $\omega-3$ fatty acids: a diseaseprevention perspective on aging-associated cardiovascular risk," Journal of Medicinal Food, vol. 21, no. 10, pp. 10601069, 2018.

[98] K. B. Pandey and S. I. Rizvi, "Plant polyphenols as dietary antioxidants in human health and disease," Oxidative Medicine and Cellular Longevity, vol. 2, no. 5, 278 pages, 2009.

[99] T. Walle, F. Hsieh, M. H. DeLegge, J. E. Oatis Jr., and U. K. Walle, "High absorption but very low bioavailability of oral resveratrol in humans," Drug Metabolism and Disposition, vol. 32, no. 12, pp. 1377-1382, 2004. 
[100] H. Doostdar, M. D. Burke, and R. T. Mayer, "Bioflavonoids: selective substrates and inhibitors for cytochrome P450 CYP1A and CYP1B1," Toxicology, vol. 144, no. 1-3, pp. 3138, 2000.

[101] J. B. Vaidyanathan and T. Walle, "Glucuronidation and sulfation of the tea flavonoid (-)-epicatechin by the human and rat enzymes," Drug Metabolism and Disposition, vol. 30, no. 8, pp. 897-903, 2002.

[102] F. Qian, D. Wei, and Q. Zhang, "Modulation of Pglycoprotein function and reversal of multidrug resistance by (-)-epigallocatechin gallate in human cancer cells," Biomedicine \& Pharmacotherapy, vol. 59, no. 3, pp. 64-69, 2005.

[103] H. M. Wortelboer, M. Usta, A. E. van der Velde et al., "Interplay between MRP inhibition and metabolism of MRP inhibitors: the case of curcumin," Chemical Research in Toxicology, vol. 16, no. 12, pp. 1642-1651, 2003.

[104] A. C. Whitley, D. H. Sweet, and T. Walle, "The dietary polyphenol ellagic acid is a potent inhibitor of hOAT1," Drug Metabolism and Disposition, vol. 33, no. 8, pp. 1097-1100, 2005.

[105] R. J. Nijveldt, E. van Nood, D. E. van Hoorn, P. G. Boelens, K. van Norren, and P. A. van Leeuwen, "Flavonoids: a review of probable mechanisms of action and potential applications," The American Journal of Clinical Nutrition, vol. 74, no. 4, pp. 418-425, 2001.

[106] P. I. Oteiza, A. G. Erlejman, S. V. Verstraeten, C. L. Keen, and C. G. Fraga, "Flavonoid-membrane interactions: a protective role of flavonoids at the membrane surface?," Clinical \& Developmental Immunology, vol. 12, no. 1, pp. 19-25, 2005.

[107] B. S. Cheon, Y. H. Kim, K. S. Son, H. W. Chang, S. S. Kang, and H. P. Kim, "Effects of prenylated flavonoids and biflavonoids on lipopolysaccharide-induced nitric oxide production from the mouse macrophage cell line RAW 264.7," Planta Medica, vol. 66, no. 7, pp. 596-600, 2000.

[108] M. P. Mattson and A. Cheng, "Neurohormetic phytochemicals: low-dose toxins that induce adaptive neuronal stress responses," Trends in Neurosciences, vol. 29, no. 11, pp. 632-639, 2006.

[109] S. Davinelli, G. Corbi, A. Zarrelli et al., "Short-term supplementation with flavanol-rich cocoa improves lipid profile, antioxidant status and positively influences the AA/EPA ratio in healthy subjects," The Journal of Nutritional Biochemistry, vol. 61, pp. 33-39, 2018.

[110] G. Corbi, V. Conti, K. Komici et al., "Phenolic Plant Extracts Induce Sirt1 Activity and Increase Antioxidant Levels in the Rabbit's Heart and Liver," Oxidative Medicine and Cellular Longevity, vol. 2018, Article ID 2731289, 10 pages, 2018.

[111] M. Karim, K. McCormick, and C. T. Kappagoda, "Effects of cocoa extracts on endothelium-dependent relaxation," The Journal of Nutrition, vol. 130, no. 8, pp. 2105S-2108S, 2000.

[112] L. Rivera, R. Morón, M. Sánchez, A. Zarzuelo, and M. Galisteo, "Quercetin ameliorates metabolic syndrome and improves the inflammatory status in obese Zucker rats," Obesity, vol. 16, no. 9, pp. 2081-2087, 2008.

[113] J. Duarte, R. Pérez-Palencia, F. Vargas et al., "Antihypertensive effects of the flavonoid quercetin in spontaneously hypertensive rats," British Journal of Pharmacology, vol. 133, no. 1, pp. 117-124, 2001.

[114] M. Sanchez, M. Galisteo, R. Vera et al., "Quercetin downregulates NADPH oxidase, increases eNOS activity and prevents endothelial dysfunction in spontaneously hypertensive rats," Journal of Hypertension, vol. 24, no. 1, pp. 75-84, 2006.

[115] J. J. Han, J. Hao, C. H. Kim, J. S. Hong, H. Y. Ahn, and Y. S. Lee, "Quercetin prevents cardiac hypertrophy induced by pressure overload in rats," The Journal of Veterinary Medical Science, vol. 71, no. 6, pp. 737-743, 2009.

[116] M. Li, Y. Jiang, W. Jing, B. Sun, C. Miao, and L. Ren, "Quercetin provides greater cardioprotective effect than its glycoside derivative rutin on isoproterenol-induced cardiac fibrosis in the rat," Canadian Journal of Physiology and Pharmacology, vol. 91, no. 11, pp. 951-959, 2013.

[117] S. K. Panchal, H. Poudyal, and L. Brown, "Quercetin ameliorates cardiovascular, hepatic, and metabolic changes in dietinduced metabolic syndrome in rats," The Journal of Nutrition, vol. 142, no. 6, pp. 1026-1032, 2012.

[118] R. L. Castillo, E. A. Herrera, A. Gonzalez-Candia et al., "Quercetin prevents diastolic dysfunction induced by a high-cholesterol diet: role of oxidative stress and bioenergetics in hyperglycemic rats," Oxidative Medicine and Cellular Longevity, vol. 2018, Article ID 7239123, 14 pages, 2018.

[119] M. Barteková, P. Šimončíková, M. Fogarassyová et al., “Quercetin improves postischemic recovery of heart function in doxorubicin-treated rats and prevents doxorubicin-induced matrix metalloproteinase- 2 activation and apoptosis induction," International Journal of Molecular Sciences, vol. 16, no. 12, pp. 8168-8185, 2015.

[120] L. Y. Dong, F. Chen, M. Xu, L. P. Yao, Y. J. Zhang, and Y. Zhuang, "Quercetin attenuates myocardial ischemiareperfusion injury via downregulation of the HMGB1TLR4-NF- $\kappa$ B signaling pathway," American Journal of Translational Research, vol. 10, no. 5, pp. 1273-1283, 2018.

[121] X. Liu, Z. Yu, X. Huang et al., "Peroxisome proliferatoractivated receptor $\gamma$ (PPAR $\gamma)$ mediates the protective effect of quercetin against myocardial ischemia-reperfusion injury via suppressing the NF- $\kappa \mathrm{B}$ pathway," American Journal of Translational Research, vol. 8, no. 12, pp. 5169-5186, 2016.

[122] H. Guo, X. Zhang, Y. Cui et al., "Taxifolin protects against cardiac hypertrophy and fibrosis during biomechanical stress of pressure overload," Toxicology and Applied Pharmacology, vol. 287, no. 2, pp. 168-177, 2015.

[123] X. Sun, R. C. Chen, Z. H. Yang et al., “Taxifolin prevents diabetic cardiomyopathy in vivo and in vitro by inhibition of oxidative stress and cell apoptosis," Food and Chemical Toxicology, vol. 63, pp. 221-232, 2014.

[124] K. Rivera, F. Salas-Pérez, G. Echeverría et al., "Red wine grape pomace attenuates atherosclerosis and myocardial damage and increases survival in association with improved plasma antioxidant activity in a murine model of lethal ischemic heart disease," Nutrients, vol. 11, no. 9, article 2135, 2019.

[125] S. Haseeb, B. Alexander, and A. Baranchuk, "Wine and cardiovascular health: a comprehensive review," Circulation, vol. 136, no. 15, pp. 1434-1448, 2017.

[126] A. Riba, L. Deres, B. Sumegi, K. Toth, E. Szabados, and R. Halmosi, "Cardioprotective effect of resveratrol in a postinfarction heart failure model," Oxidative Medicine and Cellular Longevity, vol. 2017, Article ID 6819281, 10 pages, 2017.

[127] S. Martin, E. Andriambeloson, K. Takeda, and R. Andriantsitohaina, "Red wine polyphenols increase calcium in bovine aortic endothelial cells: a basis to elucidate signalling pathways leading to nitric oxide production," British Journal of Pharmacology, vol. 135, no. 6, pp. 1579-1587, 2002. 
[128] M. Ndiaye, T. Chataigneau, M. Chataigneau, and V. B. Schini-Kerth, "Red wine polyphenols induce EDHFmediated relaxations in porcine coronary arteries through the redox-sensitive activation of the PI3-kinase/Akt pathway," British Journal of Pharmacology, vol. 142, no. 7, pp. 1131-1136, 2004.

[129] Y. Tang, J. Xu, W. Qu et al., "Resveratrol reduces vascular cell senescence through attenuation of oxidative stress by SIRT1/NADPH oxidase-dependent mechanisms," The Journal of Nutritional Biochemistry, vol. 23, no. 11, pp. 1410-1416, 2012.

[130] C. L. Kao, L. K. Chen, Y. L. Chang et al., "Resveratrol protects human endothelium from $\mathrm{H} 2 \mathrm{O} 2$-induced oxidative stress and senescence via SirT1 activation," Journal of Atherosclerosis and Thrombosis, vol. 17, no. 9, pp. 970-979, 2010.

[131] L. Cheng, Z. Jin, R. Zhao, K. Ren, C. Deng, and S. Yu, "Resveratrol attenuates inflammation and oxidative stress induced by myocardial ischemia-reperfusion injury: role of Nrf2/ARE pathway," International Journal of Clinical and Experimental Medicine, vol. 8, no. 7, pp. 10420-10428, 2015.

[132] J. Li, C. Xie, J. Zhuang et al., "Resveratrol attenuates inflammation in the rat heart subjected to ischemia-reperfusion: role of the TLR4/NF- $\kappa \mathrm{B}$ signaling pathway," Molecular Medicine Reports, vol. 11, no. 2, pp. 1120-1126, 2014.

[133] Z. J. Mao, H. Lin, J. W. Hou, Q. Zhou, Q. Wang, and Y. H. Chen, "A Meta-Analysis of Resveratrol Protects against Myocardial Ischemia/Reperfusion Injury: Evidence from Small Animal Studies and Insight into Molecular Mechanisms," Oxidative Medicine and Cellular Longevity, vol. 2019, Article ID 5793867, 11 pages, 2019.

[134] S. K. Das, W. Wang, P. Zhabyeyev et al., "Iron-overload injury and cardiomyopathy in acquired and genetic models is attenuated by resveratrol therapy," Scientific Reports, vol. 5, no. 1, article 18132, 2015.

[135] C. Zhang, Y. Feng, S. Qu et al., "Resveratrol attenuates doxorubicin-induced cardiomyocyte apoptosis in mice through SIRT1-mediated deacetylation of p53," Cardiovascular Research, vol. 90, no. 3, pp. 538-545, 2011.

[136] P. K. Gupta, D. J. DiPette, and S. C. Supowit, "Protective effect of resveratrol against pressure overload-induced heart failure," Food Science \& Nutrition, vol. 2, no. 3, pp. 218229, 2014.

[137] Q. Q. Wu, Y. Xiao, X. H. Jiang et al., "Evodiamine attenuates TGF- $\beta 1$-induced fibroblast activation and endothelial to mesenchymal transition," Molecular and Cellular Biochemistry, vol. 430, no. 1-2, pp. 81-90, 2017.

[138] S. Miriyala, M. Panchatcharam, and P. Rengarajulu, "Cardioprotective effects of curcumin," Advances in Experimental Medicine and Biology, vol. 595, pp. 359-377, 2007.

[139] N. P. Wang, Z. F. Wang, S. Tootle, T. Philip, and Z. Q. Zhao, "Curcumin promotes cardiac repair and ameliorates cardiac dysfunction following myocardial infarction," British Journal of Pharmacology, vol. 167, no. 7, pp. 1550-1562, 2012.

[140] Y. S. Kim, J. S. Kwon, Y. K. Cho et al., "Curcumin reduces the cardiac ischemia-reperfusion injury: involvement of the tolllike receptor 2 in cardiomyocytes," The Journal of Nutritional Biochemistry, vol. 23, no. 11, pp. 1514-1523, 2012.

[141] W. Duan, Y. Yang, J. Yan et al., "The effects of curcumin posttreatment against myocardial ischemia and reperfusion by activation of the JAK2/STAT3 signaling pathway," Basic Research in Cardiology, vol. 107, no. 3, p. 263, 2012.
[142] X. F. Pang, L. H. Zhang, F. Bai et al., "Attenuation of myocardial fibrosis with curcumin is mediated by modulating expression of angiotensin II AT1/AT2 receptors and ACE2 in rats," Drug Design, Development and Therapy, vol. 9, pp. 6043-6054, 2015.

[143] F. H. Lv, H. L. Yin, Y. Q. He et al., "Effects of curcumin on the apoptosis of cardiomyocytes and the expression of NF- $\kappa \mathrm{B}$, PPAR- $\gamma$ and Bcl-2 in rats with myocardial infarction injury," Experimental and Therapeutic Medicine, vol. 12, no. 6, pp. 3877-3884, 2016.

[144] T. Morimoto, Y. Sunagawa, T. Kawamura et al., "The dietary compound curcumin inhibits p300 histone acetyltransferase activity and prevents heart failure in rats," The Journal of Clinical Investigation, vol. 118, no. 3, pp. 868-878, 2008.

[145] J. Xiao, X. Sheng, X. Zhang, M. Guo, and X. Ji, "Curcumin protects against myocardial infarction-induced cardiac fibrosis via SIRT1 activation in vivo and in vitro," Drug Design, Development and Therapy, vol. 10, pp. 1267-1277, 2016.

[146] Y. Sun, X. Hu, G. Hu, C. Xu, and H. Jiang, "Curcumin attenuates hydrogen peroxide-induced premature senescence via the activation of SIRT1 in human umbilical vein endothelial cells," Biological \& Pharmaceutical Bulletin, vol. 38, no. 8, pp. 1134-1141, 2015.

[147] Y. Sunagawa, S. Sono, Y. Katanasaka et al., "Optimal dosesetting study of curcumin for improvement of left ventricular systolic function after myocardial infarction in rats," Journal of Pharmacological Sciences, vol. 126, no. 4, pp. 329-336, 2014.

[148] P. M. Boarescu, I. Chirilă, A. E. Bulboacă et al., "Effects of curcumin nanoparticles in isoproterenol-induced myocardial infarction," Oxidative Medicine and Cellular Longevity, vol. 2019, Article ID 7847142, 13 pages, 2019.

[149] R. L. Edwards, T. Lyon, S. E. Litwin, A. Rabovsky, J. D. Symons, and T. Jalili, "Quercetin reduces blood pressure in hypertensive subjects," The Journal of Nutrition, vol. 137, no. 11, pp. 2405-2411, 2007.

[150] V. Brüll, C. Burak, B. Stoffel-Wagner et al., "Effects of a quercetin-rich onion skin extract on $24 \mathrm{~h}$ ambulatory blood pressure and endothelial function in overweight-to-obese patients with (pre-)hypertension: a randomised doubleblinded placebo-controlled cross-over trial," British Journal of Nutrition, vol. 114, no. 8, pp. 1263-1277, 2015.

[151] V. E. Kondratiuk and Y. P. Synytsia, "Effect of quercetin on the echocardiographic parameters of left ventricular diastolic function in patients with gout and essential hypertension," Wiadomości Lekarskie, vol. 71, no. 8, pp. 1554-1559, 2018.

[152] N. I. Chekalina, S. V. Shut, T. A. Trybrat et al., "Effect of quercetin on parameters of central hemodynamics and myocardial ischemia in patients with stable coronary heart disease," Wiadomości Lekarskie, vol. 70, no. 4, pp. 707$711,2017$.

[153] N. Chekalina, Y. Burmak, Y. Petrov et al., "Quercetin reduces the transcriptional activity of NF-kB in stable coronary artery disease," Indian Heart Journal, vol. 70, no. 5, pp. 593-597, 2018.

[154] W. Wongcharoen, S. Jai-Aue, A. Phrommintikul et al., "Effects of curcuminoids on frequency of acute myocardial infarction after coronary artery bypass grafting," The American Journal of Cardiology, vol. 110, no. 1, pp. 40-44, 2012.

[155] K. Fujitaka, H. Otani, F. Jo et al., "Modified resveratrol Longevinex improves endothelial function in adults with 
metabolic syndrome receiving standard treatment," Nutrition Research, vol. 31, no. 11, pp. 842-847, 2011.

[156] J. Tome-Carneiro, M. Gonzalvez, M. Larrosa et al., "Grape resveratrol increases serum adiponectin and downregulates inflammatory genes in peripheral blood mononuclear cells: a triple-blind, placebo-controlled, one-year clinical trial in patients with stable coronary artery disease," Cardiovascular Drugs and Therapy, vol. 27, no. 1, pp. 37-48, 2013.

[157] C. Militaru, I. Donoiu, A. Craciun, I. D. Scorei, A. M. Bulearca, and R. I. Scorei, "Oral resveratrol and calcium fructoborate supplementation in subjects with stable angina pectoris: effects on lipid profiles, inflammation markers, and quality of life," Nutrition, vol. 29, no. 1, pp. 178-183, 2013.

[158] K. Magyar, R. Halmosi, A. Palfi et al., "Cardioprotection by resveratrol: a human clinical trial in patients with stable coronary artery disease," Clinical Hemorheology and Microcirculation, vol. 50, no. 3, pp. 179-187, 2012.

[159] A. J. Flammer, I. Sudano, M. Wolfrum et al., "Cardiovascular effects of flavanol-rich chocolate in patients with heart failure," European Heart Journal, vol. 33, no. 17, pp. 21722180, 2012.

[160] F. Potì, D. Santi, G. Spaggiari, F. Zimetti, and I. Zanotti, "Polyphenol health effects on cardiovascular and neurodegenerative disorders: a review and meta-analysis," International Journal of Molecular Sciences, vol. 20, no. 2, p. 351, 2019.

[161] R. E. Ostlund Jr., J. B. McGill, C. M. Zeng et al., "Gastrointestinal absorption and plasma kinetics of soy $\Delta^{5}$-phytosterols and phytostanols in humans," American Journal of Physiology Endocrinology and Metabolism, vol. 282, no. 4, pp. E911-E916, 2002.

[162] M. Rocha, C. Banuls, L. Bellod, A. Jover, V. M. Victor, and A. Hernandez-Mijares, "A review on the role of phytosterols: new insights into cardiovascular risk," Current Pharmaceutical Design, vol. 17, no. 36, pp. 4061-4075, 2011.

[163] C. E. Cabral, "Phytosterols in the treatment of hypercholesterolemia and prevention of cardiovascular diseases," Arquivos Brasileiros de Cardiologia, vol. 109, no. 5, pp. 475-482, 2017.

[164] T. Sudhop, B. M. Gottwald, and K. von Bergmann, "Serum plant sterols as a potential risk factor for coronary heart disease," Metabolism, vol. 51, no. 12, pp. 1519-1521, 2002.

[165] S. Pinedo, M. N. Vissers, K. von Bergmann et al., "Plasma levels of plant sterols and the risk of coronary artery disease: the prospective EPIC-Norfolk Population Study," Journal of Lipid Research, vol. 48, no. 1, pp. 139-144, 2007.

[166] E. Windler, B. C. Zyriax, F. Kuipers, J. Linseisen, and H. Boeing, "Association of plasma phytosterol concentrations with incident coronary heart disease: Data from the CORA study, a case-control study of coronary artery disease in women," Atherosclerosis, vol. 203, no. 1, pp. 284-290, 2009.

[167] K. Fassbender, D. Lütjohann, M. G. Dik et al., "Moderately elevated plant sterol levels are associated with reduced cardiovascular risk-The LASA study," Atherosclerosis, vol. 196, no. 1, pp. 283-288, 2008.

[168] V. Escurriol, M. Cofán, C. Moreno-Iribas et al., "Phytosterol plasma concentrations and coronary heart disease in the prospective Spanish EPIC cohort," Journal of Lipid Research, vol. 51, no. 3, pp. 618-624, 2010.

[169] B. Genser, G. Silbernagel, G. De Backer et al., "Plant sterols and cardiovascular disease: a systematic review and meta- analysis," European Heart Journal, vol. 33, no. 4, pp. 444451, 2012.

[170] O. T. Raitakari, P. Salo, H. Gylling, and T. A. Miettinen, "Plant stanol ester consumption and arterial elasticity and endothelial function," British Journal of Nutrition, vol. 100, no. 3, pp. 603-608, 2008.

[171] M. Hallikainen, T. Lyyra-Laitinen, T. Laitinen, L. Moilanen, T. A. Miettinen, and H. Gylling, "Effects of plant stanol esters on serum cholesterol concentrations, relative markers of cholesterol metabolism and endothelial function in type 1 diabetes," Atherosclerosis, vol. 199, no. 2, pp. 432-439, 2008.

[172] H. Gylling, J. Halonen, H. Lindholm et al., "The effects of plant stanol ester consumption on arterial stiffness and endothelial function in adults: a randomised controlled clinical trial," BMC Cardiovascular Disorders, vol. 13, no. 1, pp. 5050, 2013.

[173] R. T. Ras, D. Fuchs, W. P. Koppenol et al., "The effect of a low-fat spread with added plant sterols on vascular function markers: results of the Investigating Vascular Function Effects of Plant Sterols (INVEST) study," The American Journal of Clinical Nutrition, vol. 101, no. 4, pp. 733-741, 2015.

[174] V. Z. Rocha, R. T. Ras, A. C. Gagliardi, L. C. Mangili, E. A. Trautwein, and R. D. Santos, "Effects of phytosterols on markers of inflammation: a systematic review and meta-analysis," Atherosclerosis, vol. 248, pp. 76-83, 2016.

[175] S. Baumgartner, R. T. Ras, E. A. Trautwein, R. P. Mensink, and J. Plat, "Plasma fat-soluble vitamin and carotenoid concentrations after plant sterol and plant stanol consumption: a meta-analysis of randomized controlled trials," European Journal of Nutrition, vol. 56, no. 3, pp. 909-923, 2017.

[176] Y. Yoshida and E. Niki, "Antioxidant effects of phytosterol and its components," Journal of Nutritional Science and Vitaminology, vol. 49, no. 4, pp. 277-280, 2003.

[177] R. Pfister, S. J. Sharp, R. Luben, N. J. Wareham, and K. T. Khaw, "Plasma vitamin C predicts incident heart failure in men and women in European Prospective Investigation into Cancer and Nutrition-Norfolk prospective study," American Heart Journal, vol. 162, no. 2, pp. 246-253, 2011.

[178] S. Rautiainen, E. B. Levitan, M. A. Mittleman, and A. Wolk, "Fruit and vegetable intake and rate of heart failure: a population-based prospective cohort of women," European Journal of Heart Failure, vol. 17, no. 1, pp. 20-26, 2015.

[179] K. M. Lara, E. B. Levitan, O. M. Gutierrez et al., "Dietary patterns and incident heart failure in U.S. Adults without known coronary disease," Journal of the American College of Cardiology, vol. 73, no. 16, pp. 2036-2045, 2019.

[180] Y. Wang, J. Tuomilehto, P. Jousilahti et al., "Lifestyle factors in relation to heart failure among Finnish men and women," Circulation: Heart Failure, vol. 4, no. 5, pp. 607-612, 2011.

[181] L. Djousse, J. A. Driver, and J. M. Gaziano, "Relation between modifiable lifestyle factors and lifetime risk of heart failure," Journal of the American Medical Association, vol. 302, no. 4, pp. 394-400, 2009.

[182] K. Sharma and D. A. Kass, "Heart failure with preserved ejection fraction: mechanisms, clinical features, and therapies," Circulation, vol. 115, no. 1, pp. 79-96, 2014.

[183] J. Kobayashi, K. Ohtake, and H. Uchida, "NO-rich diet for lifestyle-related diseases," Nutrients, vol. 7, no. 6, pp. 49114937, 2015.

[184] S. L. Hummel, E. M. Seymour, R. D. Brook et al., "Lowsodium dietary approaches to stop hypertension diet reduces 
blood pressure, arterial stiffness, and oxidative stress in hypertensive heart failure with preserved ejection fraction," Hypertension, vol. 60, no. 5, pp. 1200-1206, 2012.

[185] O. P. Soldin and D. R. Mattison, "Sex differences in pharmacokinetics and pharmacodynamics," Clinical Pharmacokinetics, vol. 48, no. 3, pp. 143-157, 2009.

[186] I. Campesi, M. Marino, M. Cipolletti, A. Romani, and F. Franconi, "Put "gender glasses" on the effects of phenolic compounds on cardiovascular function and diseases," European Journal of Nutrition, vol. 57, no. 8, pp. 2677-2691, 2018.

[187] J. M. Geleijnse, L. J. Launer, A. Hofman, H. A. Pols, and J. C. Witteman, "Tea flavonoids may protect against atherosclerosis: the Rotterdam Study," Archives of Internal Medicine, vol. 159, no. 18, pp. 2170-2174, 1999.

[188] J. M. Geleijnse, J. C. Witteman, L. J. Launer, S. W. Lamberts, and H. A. Pols, "Tea and coronary heart disease: protection through estrogen-like activity?," Archives of Internal Medicine, vol. 160, no. 21, pp. 3328-3329, 2000.

[189] I. Erlund, T. Kosonen, G. Alfthan et al., "Pharmacokinetics of quercetin from quercetin aglycone and rutin in healthy volunteers," European Journal of Clinical Pharmacology, vol. 56, no. 8, pp. 545-553, 2000.

[190] M. Forte, V. Conti, A. Damato et al., "Targeting nitric oxide with natural derived compounds as a therapeutic strategy in vascular diseases," Oxidative Medicine and Cellular Longevity, vol. 2016, Article ID 7364138, 20 pages, 2016.

[191] J. R. Santos-Parker, T. R. Strahler, C. J. Bassett, N. Z. Bispham, M. B. Chonchol, and D. R. Seals, "Curcumin supplementation improves vascular endothelial function in healthy middle-aged and older adults by increasing nitric oxide bioavailability and reducing oxidative stress," Aging, vol. 9, no. 1, pp. 187-208, 2017.

[192] S. L. Ramírez-Garza, E. P. Laveriano-Santos, M. MarhuendaMuñoz et al., "Health effects of resveratrol: results from human intervention trials," Nutrients, vol. 10, no. 12, article 1892, 2018.

[193] R. Menezes, A. Rodriguez-Mateos, A. Kaltsatou et al., "Impact of Flavonols on cardiometabolic biomarkers: a meta-analysis of randomized controlled human trials to explore the role of Inter-Individual variability," Nutrients, vol. 9, no. 2, p. 117, 2017.

[194] M. Zahedi, R. Ghiasvand, A. Feizi, G. Asgari, and L. Darvish, "Does quercetin improve cardiovascular risk factors and Inflammatory biomarkers in women with type 2 diabetes: a Double-blind randomized controlled clinical trial," International Journal of Preventive Medicine, vol. 4, no. 7, pp. 777785, 2013.

[195] C. Nagata, H. Shimizu, R. Takami, M. Hayashi, N. Takeda, and K. Yasuda, "Association of blood pressure with intake of soy products and other food groups in Japanese men and women," Preventive Medicine, vol. 36, no. 6, pp. 692-697, 2003.

[196] M. Rivas, R. P. Garay, J. F. Escanero, P. Cia Jr., P. Cia, and J. O. Alda, "Soy milk lowers blood pressure in men and women with mild to moderate essential hypertension," The Journal of Nutrition, vol. 132, no. 7, pp. 1900-1902, 2002.

[197] A. Alonso and M. A. Martinez-Gonzalez, "Olive oil consumption and reduced incidence of hypertension: the SUN study," Lipids, vol. 39, no. 12, pp. 1233-1238, 2004.

[198] L. M. Ostertag, P. A. Kroon, S. Wood et al., "Flavan-3-olenriched dark chocolate and white chocolate improve acute measures of platelet function in a gender-specific way-a randomized-controlled human intervention trial," Molecular Nutrition \& Food Research, vol. 57, no. 2, pp. 191-202, 2013.

[199] M. L. McCullough, J. J. Peterson, R. Patel, P. F. Jacques, R. Shah, and J. T. Dwyer, "Flavonoid intake and cardiovascular disease mortality in a prospective cohort of US adults," The American Journal of Clinical Nutrition, vol. 95, no. 2, pp. 454-464, 2012.

[200] E. A. Trautwein, M. A. Vermeer, H. Hiemstra, and R. T. Ras, "LDL-cholesterol lowering of plant sterols and stanols-which factors influence their efficacy?," Nutrients, vol. 10, no. 9, article 1262, 2018.

[201] R. Liew, M. A. Stagg, J. Chan, P. Collins, and K. T. MacLeod, "Gender determines the acute actions of genistein on intracellular calcium regulation in the guinea-pig heart," Cardiovascular Research, vol. 61, no. 1, pp. 66-76, 2004.

[202] B. L. Stauffer, J. P. Konhilas, E. D. Luczak, and L. A. Leinwand, "Soy diet worsens heart disease in mice," The Journal of Clinical Investigation, vol. 116, no. 1, pp. 209-216, 2006.

[203] M. C. Olsson, B. M. Palmer, L. A. Leinwand, and R. L. Moore, "Gender and aging in a transgenic mouse model of hypertrophic cardiomyopathy," American Journal of Physiology Heart and Circulatory Physiology, vol. 280, no. 3, pp. H1136H1144, 2001. 


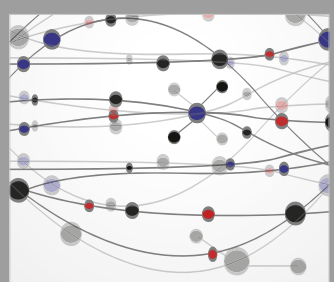

The Scientific World Journal
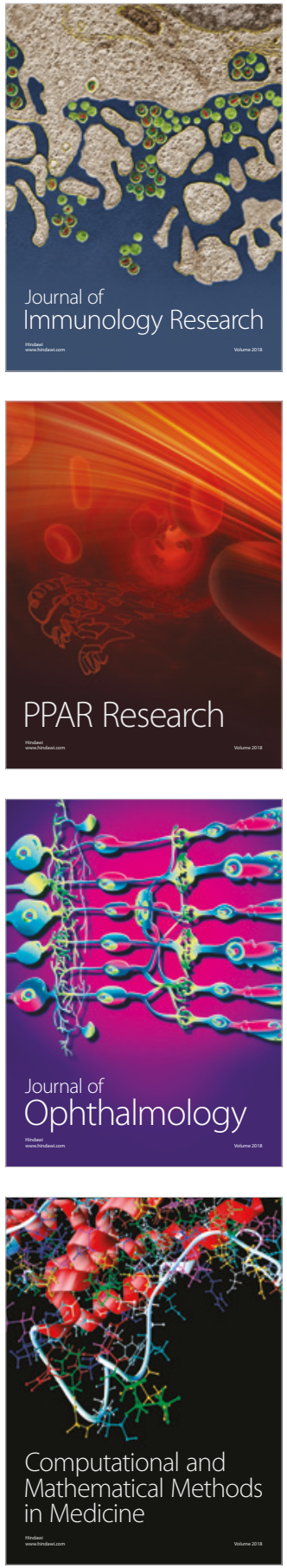

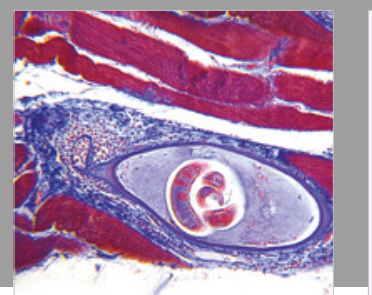

Gastroenterology Research and Practice

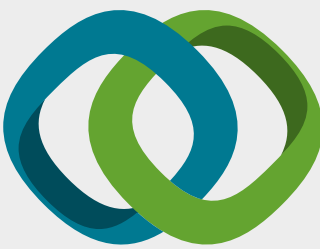

\section{Hindawi}

Submit your manuscripts at

www.hindawi.com
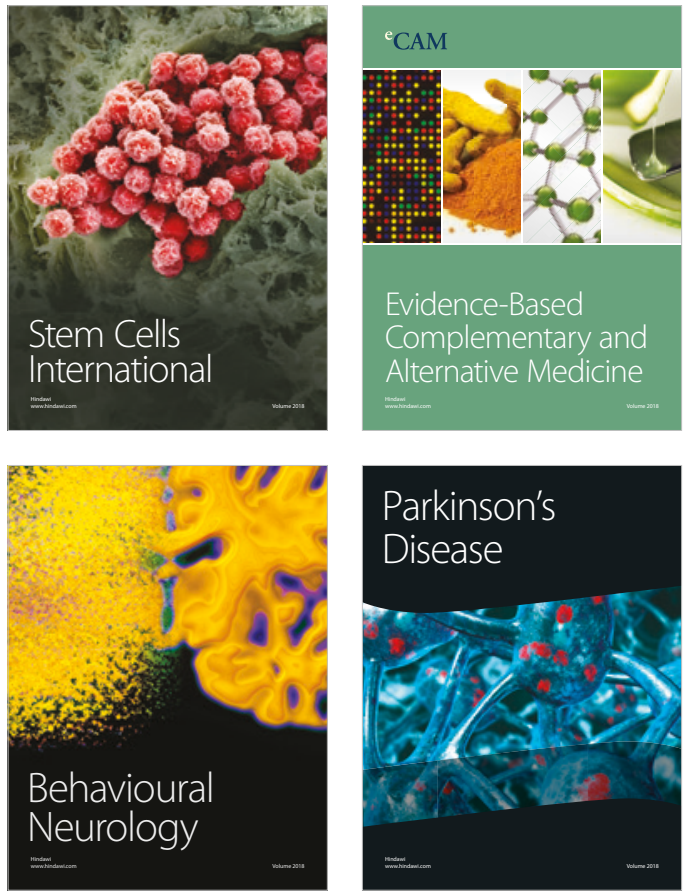

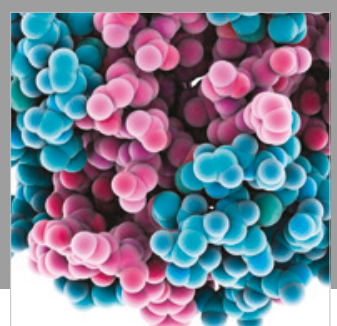

ournal of

Diabetes Research

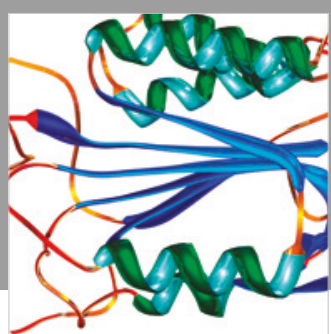

Disease Markers
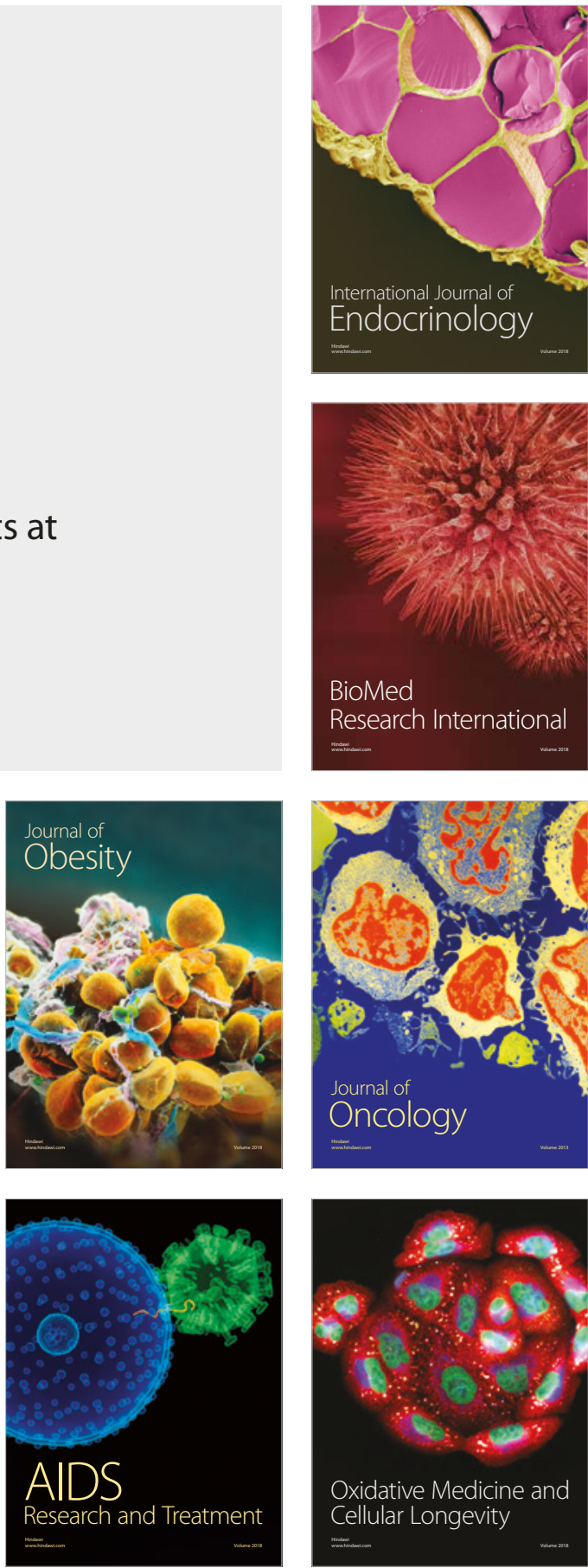